Article

\title{
Solid-State Nonlinear Optical Properties of Mononuclear Copper(II) Complexes with Chiral Tridentate and Tetradentate Schiff Base Ligands
}

\author{
Luca Rigamonti $^{1,2, *(\mathbb{D}}$, Alessandra Forni $\left.{ }^{2,3}{ }^{(}\right)$, Elena Cariati ${ }^{2}\left(\mathbb{D}\right.$, Gianluca Malavasi $^{1}$ and \\ Alessandro Pasini ${ }^{2}$ \\ 1 Dipartimento di Scienze Chimiche e Geologiche, Università degli Studi di Modena e Reggio Emilia, \\ via G. Campi 103, 41125 Modena, Italy; gianluca.malavasi@unimore.it \\ 2 Dipartimento di Chimica, Università degli Studi di Milano, via C. Golgi 19, 20133 Milano, Italy; \\ alessandra.forni@istm.cnr.it (A.F.); elena.cariati@unimi.it (E.C.); alessandro.pasini@unimi.it (A.P.) \\ 3 Istituto di Scienze e Tecnologie Molecolari, Consiglio Nazionale delle Ricerche, via C. Golgi 19, 20133 Milano, \\ Italy \\ * Correspondence: luca.rigamonti@unimore.it or luca.rigamonti@yahoo.com; Tel.: +39-059-205-8646
}

Received: 8 October 2019; Accepted: 29 October 2019; Published: 1 November 2019

\begin{abstract}
Salen-type metal complexes have been actively studied for their nonlinear optical (NLO) properties, and push-pull compounds with charge asymmetry generated by electron releasing and withdrawing groups have shown promising results. As a continuation of our research in this field and aiming at solid-state features, herein we report on the synthesis of mononuclear copper(II) derivatives bearing either tridentate $\mathrm{N}_{2} \mathrm{O}$ Schiff bases $\mathrm{L}^{(\mathrm{a}-\mathrm{c})-}$ and pyridine as the forth ancillary ligand, $\left[\mathrm{Cu}\left(\mathrm{L}^{\mathrm{a}-\mathrm{c}}\right)(\mathrm{py})\right]\left(\mathrm{ClO}_{4}\right)(\mathbf{1 a}-\mathrm{c})$, or unsymmetrically-substituted push-pull tetradentate $\mathrm{N}_{2} \mathrm{O}_{2}$ Schiff base ligands, [Cu(5-A-5'-D-saldpen/chxn)] (2a-c), both derived from 5-substituted salicylaldehydes (sal) and the diamines (1R,2R)-1,2-diphenylethanediamine (dpen) and (1S,2S)-1,2-diaminocyclohexane (chxn). All compounds were characterized through elemental analysis, infrared and UV/visible spectroscopies, and mass spectrometry in order to guarantee their purity and assess their charge transfer properties. The structures of $\mathbf{1 a}-\mathbf{c}$ were determined via single-crystal $\mathrm{X}$-ray diffraction studies. The geometries of cations of $\mathbf{1 a}-\mathbf{c}$ and of molecules $\mathbf{2 a - c}$ were optimized through DFT calculations. The solid-state NLO behavior was measured by the Kurtz-Perry powder technique @1.907 $\mu \mathrm{m}$. All chiral derivatives possess non-zero quadratic electric susceptibility $\left(\chi^{(2)}\right)$ and an efficiency of about $0.15-0.45$ times that of standard urea.
\end{abstract}

Keywords: chiral diamines; template synthesis; mononuclear copper(II) complexes; Schiff base ligands; nonlinear optics; Kurtz-Perry powder technique

\section{Introduction}

Since the generation of optical harmonics by the interactions of a ruby optical maser [1] with crystalline quartz [2], the research in the nonlinear optics (NLO) field [3] has grown exponentially [4-9]. One of the most extensively applied features of NLO materials is the generation of second harmonic (SHG) radiation, that is, the process where the frequency $\omega$ of an incident radiation becomes $2 \omega$ when passing through the medium [3]. Molecular compounds able to show and maximize such an NLO effect in the solid state have to possess high molecular quadratic hyperpolarizabily $(\beta)$ values together with a non-centrosymmetric crystal packing [10], able to guarantee the final non-zero quadratic electric susceptibility $\left(\chi^{(2)}\right)$ of the bulk material $[7,8]$.

Among other organometallic [11-15] and coordination compounds [14-18], salen-type [19] metal complexes have been actively studied for their NLO properties, mostly for the last two 
decades $[17,18,20-23]$. The best functionalization of these derivatives has been achieved by inserting donor (D) groups on the salicylaldehyde (sal) moieties and acceptor (A) groups on the diamine bridge, such as substituted 1,2-diaminobenzene (phen) and diaminomaleonitrile (damn). Such push-pull bis(salicylaldiminato) metal complexes with charge asymmetry generated by electron releasing and withdrawing groups on the ligand skeleton have shown promising results for their SHG efficiency in solution through electric field induced second harmonic (EFISH) generation and hyper rayleigh scattering (HRS) measurements [24-33]. This class of compounds has also been the subject of extensive theoretical studies through the years in order to elucidate their electronic and optical features $[17,26,32,34-37]$. As an alternative to the above-mentioned push-pull structure, we focused our attention on salen-type metal complexes in which the A-D asymmetry is achieved by push-pull unsymmetrical substitution on the sal moieties, firstly on copper(II) derivatives [38], and very recently also on nickel(II) compounds [39]. Other examples have also applied such an approach with different designs and synthetic strategies [21,40-44].

After the first evidences of the role of salen-type complexes in solid-state NLO measurements [45,46] and the promising results in solution [24-27], the first real attempt to engineer this class of compounds for solid-state applications shortly arrived by Lacroix et al., by introducing the chiral

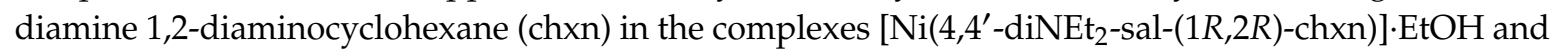
$\left[\mathrm{Mn}(\mathrm{Cl})\left(4,4^{\prime}\right.\right.$ - $\mathrm{diNEt}_{2}$-sal-(1R,2R)-chxn)], which ensures the crystallization of the two compounds in the non-centrosymmetric monoclinic $P 2_{1}$ and orthorhombic $P 2_{1} 2_{1} 2_{1}$ space groups, respectively. Their bulk NLO response was measured by the Kurtz-Perry technique [47], and their powder SHG efficiencies were $<0.25$ and $8 @ 1.907 \mu \mathrm{m}$ and 0.1 and $0.5 @ 1.064 \mu \mathrm{m}$ that of standard urea, respectively. The reduction of the efficiencies @1.064 $\mu \mathrm{m}$ was explained by absorption phenomena [23,48]. The derivative [Ni(4,4' ${ }^{\prime}$-diNEt ${ }_{2}$-sal-(1R,2R)-dpen)] with 1,2-diphenylethylenediamine (dpen) was then synthesized by changing the chemical nature of the chiral diamine, and studied for its solid-state NLO response. The powder SHG efficiency @1.907 $\mu$ m of this nickel(II) complex, which crystallizes in the monoclinic $P 2_{1}$ space group, is 13 times that of urea [23,49], close to the upper limit [10] in this class of complexes [17]. As a reference, 3-methyl-4-nitropyridine-1-oxide (POM), a molecular material that entered the market also thanks to its transparency and ability to be grown as large crystals, has a large SHG efficiency equal to 13 times that of urea [50].

Salen-type copper(II) complexes with chiral diamines have also been known for several decades [51-56]. They have been studied in particular for catalysis [56-60] and, in some cases, for biological applications [61-63]. Among them, there are also two examples studied for their NLO properties, a homodinuclear $\mathrm{Cu}_{2}$ compound, which unfortunately crystallizes in a centrosymmetric space group [64], and a heterodinuclear CuGd complex, whose SHG efficiency reaches 0.3 times that of urea [65]. Nevertheless, to the best of our knowledge, there are no examples of chiral mononuclear copper(II) compounds studied for their solid-state NLO features. In this work, we extend our previous studies on unsymmetrically-substituted salen derivatives [38] using chiral diamines, dpen and chxn, as a bridge between the imine nitrogen donor atoms (see Scheme 1) in the substitution of the aliphatic ethylenediamine (en) and 1,3-diaminopropane (tn).

Both dpen and chxn exist in three stereoisomers, $(1 R, 2 R)$ and $(1 S, 2 S)$ enantiomers and $(1 S, 2 R)$ mesomeric form. In the light of all the multiple combinations of possible $\mathrm{A} / \mathrm{D}$ groups and chirality given by the diamines, we decided to focus our efforts on representative compounds, first of all by keeping $\mathrm{NO}_{2}$ as the acceptor group, thanks to its fundamental role in both the enhancement of the molecular NLO response $\beta$ and the intensity of the ligand-to-metal charge transfer (LMCT) band [38]. We then selected $(1 R, 2 R)-(+)$-dpen and $(1 S, 2 S)-(+)$-chxn as diamines, and the insertion of the OMe group was evaluated for its cooperative effect with $\mathrm{NO}_{2}$. The synthetic intermediates $\left[\mathrm{Cu}\left(\mathrm{L}^{\mathrm{a}-\mathrm{c}}\right)(\mathrm{py})\right]\left(\mathrm{ClO}_{4}\right)$ $(\mathbf{1 a}-\mathbf{c})$, with tridentate $\mathrm{N}_{2} \mathrm{O}$ Schiff base ligands $\mathrm{L}^{(\mathrm{a}-\mathrm{c})-}$ and pyridine as the forth ancillary ligand, and the final copper(II) complexes [Cu(5-A-5'-D-saldpen/chxn)] (2a-c), with unsymmetrically-substituted tetradentate $\mathrm{N}_{2} \mathrm{O}_{2}$ Schiff base ligands, are reported in Scheme 1. Furthermore, both final push-pull 
compounds $\mathbf{2 a}-\mathbf{c}$ and intermediates $\mathbf{1 a}-\mathbf{c}$ were tested for their solid-state NLO response by measuring their SHG efficiency through the Kurtz-Perry technique.
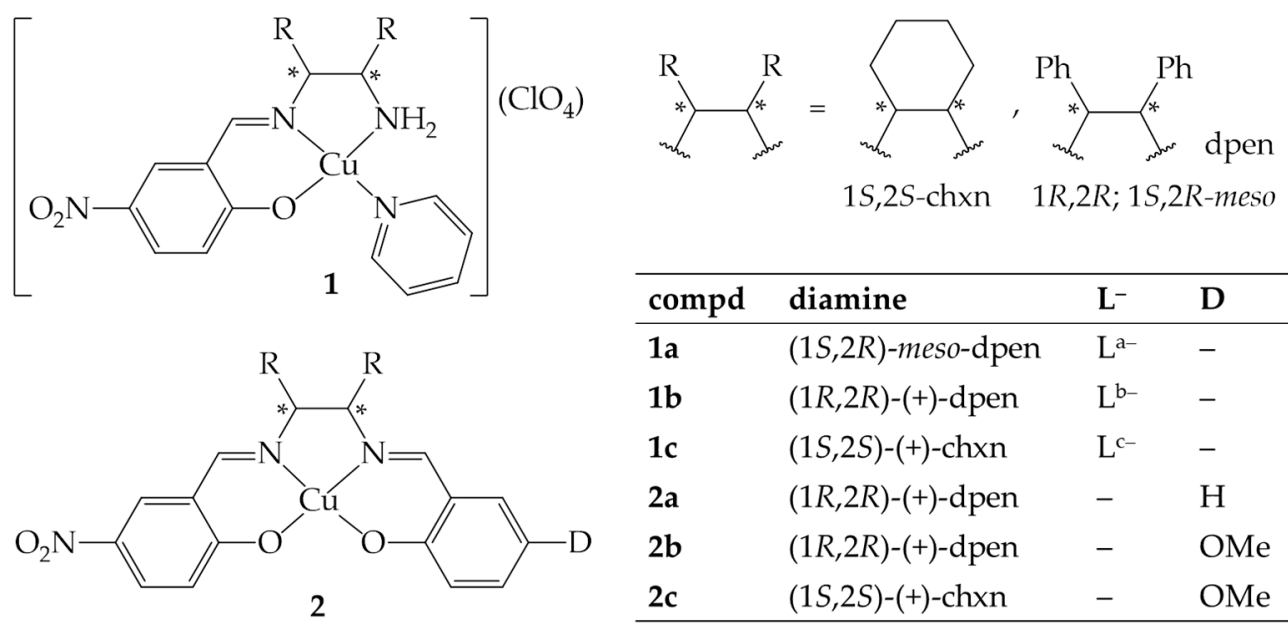

\begin{tabular}{llll}
\hline compd & diamine & $\mathbf{L}^{-}$ & $\mathbf{D}$ \\
\hline $\mathbf{1 a}$ & $(1 S, 2 R)$-meso-dpen & $\mathrm{L}^{\mathrm{a}-}$ & - \\
$\mathbf{1 b}$ & $(1 R, 2 R)-(+)$-dpen & $\mathrm{L}^{\mathrm{b}-}$ & - \\
$\mathbf{1 c}$ & $(1 S, 2 S)-(+)-\mathrm{ch} \times \mathrm{n}$ & $\mathrm{L}^{\mathrm{c}-}$ & - \\
$\mathbf{2 a}$ & $(1 R, 2 R)-(+)$-dpen & - & $\mathrm{H}$ \\
$\mathbf{2 b}$ & $(1 R, 2 R)-(+)$-dpen & - & $\mathrm{OMe}$ \\
$\mathbf{2 c}$ & $(1 S, 2 S)-(+)-\mathrm{ch} \times \mathrm{n}$ & - & $\mathrm{OMe}$ \\
\hline
\end{tabular}

Scheme 1. Schemes of compounds $\left[\mathrm{Cu}\left(\mathrm{L}^{\mathrm{a}-\mathrm{c}}\right)(\mathrm{py})\right]\left(\mathrm{ClO}_{4}\right)(\mathbf{1} \mathbf{a}-\mathbf{c})$ and $\left[\mathrm{Cu}\left(5-\mathrm{A}-5^{\prime}-\mathrm{D}-\right.\right.$ saldpen/chxn $\left.)\right](\mathbf{2 a}-\mathbf{c})$, the object of this work.

\section{Materials and Methods}

\subsection{General Information}

All chemicals were reagent grade purchased from Sigma Aldrich (purity $\geq 97 \%$ ) and solvents (methanol, $\mathrm{MeOH}$; diisopropyl ether, $i \mathrm{Pr}_{2} \mathrm{O}$ ) were used as received. Elemental analyses were performed at the Mycroanalytical Laboratory of the Università degli Studi di Milano. Electrospray ionization mass spectrometry (ESI-MS) experiments were performed with an LCQ Advantage Thermofluxional Instrument (Thermo Scientific, Waltham, USA) on MeOH solutions of the compounds (Figure S1 in Supplementary Materials, SM). Infrared (IR) spectra were recorded as $\mathrm{KBr}$ disks using a Jasco FT-IR 410 spectrophotometer (Jasco, Tokyo, Japan) with a $2 \mathrm{~cm}^{-1}$ resolution (Figure S2 in SM). UV/visible spectra were recorded at $298 \mathrm{~K}$ with a Jasco V-570 UV/Vis/NIR spectrophotometer (Jasco, Tokyo, Japan) both in reflectance (solid samples) and in transmittance (solution samples) modes in the 200-900 nm range; solution studies were performed on $\mathbf{1 b}$ and $1 \mathrm{c}$ from $10^{-3}$ to $4 \times 10^{-5} \mathrm{~mol} \mathrm{~L}^{-1} \mathrm{MeOH}$ solutions and then by addition of increasing pyridine amounts to the $4 \times 10^{-5} \mathrm{~mol} \mathrm{~L}^{-1} \mathrm{MeOH}$ solutions, and on 2a-c from $10^{-3}$ to $2 \times 10^{-5} \mathrm{~mol} \mathrm{~L}^{-1} \mathrm{CHCl}_{3}$ solutions; $\lambda$ values are accurate to $\pm 1 \mathrm{~nm}$ and spectra are reported as wavenumbers, in $\mathrm{cm}^{-1}\left(\varepsilon, \mathrm{L} \mathrm{mol}^{-1} \mathrm{~cm}^{-1}\right)$.

\subsection{Synthesis of $\left[\mathrm{Cu}\left(\mathrm{L}^{a}\right)(\mathrm{py})\right]\left(\mathrm{ClO}_{4}\right)(\mathbf{1 a})$}

An aqueous solution $(2 \mathrm{~mL})$ of $\mathrm{Cu}\left(\mathrm{ClO}_{4}\right)_{2} 6 \mathrm{H}_{2} \mathrm{O}(250 \mathrm{mg}, 0.67 \mathrm{mmol})$ and py $(162 \mu \mathrm{L}, 2.01 \mathrm{mmol})$ was added to a stirred solution of $5-\mathrm{NO}_{2}-\mathrm{salH}(112 \mathrm{mg}, 0.67 \mathrm{mmol})$ in $\mathrm{MeOH}(7 \mathrm{~mL})$. The mixture was stirred at room temperature for $1 \mathrm{~h}$ when $(1 S, 2 R)$-meso-dpen $(141 \mathrm{mg}, 0.67 \mathrm{mmol})$ was added; after $3 \mathrm{~h}$ under stirring at room temperature, the dark solution was left aside to slow evaporation for three days until the title compound was precipitated as black needles (suitable for X-ray diffraction), filtered, washed with $\mathrm{MeOH}$ and $i \operatorname{Pr}_{2} \mathrm{O}$, and dried under vacuum $(260 \mathrm{mg}, 65 \%$ ). ESI-MS (MeOH): $\mathrm{m} / z 423$ $\left(\left[\mathrm{Cu}\left(\mathrm{L}^{\mathrm{a}}\right)\right]^{+}, 70 \%\right), 455\left(\left[\mathrm{Cu}\left(\mathrm{L}^{\mathrm{a}}\right)(\mathrm{MeOH})\right]^{+}, 75\right), 845\left(\left[\mathrm{Cu}_{2}\left(\mathrm{~L}^{\mathrm{a}}\right)_{2}-\mathrm{H}\right]^{+}, 100\right)$. Elemental analysis calcd $(\%)$ for $\mathrm{C}_{26} \mathrm{H}_{23} \mathrm{~N}_{4} \mathrm{O}_{7} \mathrm{CuCl} \cdot \mathrm{MeOH} \cdot \frac{1}{2} \mathrm{H}_{2} \mathrm{O}$ (643.54): $\mathrm{C}, 50.39 ; \mathrm{H}, 4.39 ; \mathrm{N}, 8.71$. Found: $\mathrm{C}, 50.30 ; \mathrm{H}, 3.85 ; \mathrm{N}$, 8.60. FT-IR (KBr): $v\left(\mathrm{NH}_{2}\right) 3319,3267, v(\mathrm{C}=\mathrm{N}) 1634,1607, v\left(\mathrm{NO}_{2}\right) 1315, v\left(\mathrm{ClO}_{4}\right) 1103 \mathrm{~cm}^{-1}$. 


\subsection{Synthesis of $\left[\mathrm{Cu}\left(\mathrm{L}^{b}\right)(\mathrm{py})\right]\left(\mathrm{ClO}_{4}\right)(\mathbf{1} \boldsymbol{b})$ and Isolation of $\left[\mathrm{Cu}\left(\mathrm{L}^{b}\right)\left(\mathrm{H}_{2} \mathrm{O}\right)\right]\left(\mathrm{ClO}_{4}\right)\left(\mathbf{1} \boldsymbol{b}^{\prime}\right)$ as Intermediate}

An aqueous solution $(2.5 \mathrm{~mL})$ of $\mathrm{Cu}\left(\mathrm{ClO}_{4}\right)_{2} 6 \mathrm{H}_{2} \mathrm{O}(360.0 \mathrm{mg}, 0.97 \mathrm{mmol})$ and py $(235 \mu \mathrm{L}, 2.91 \mathrm{mmol})$ was added to a stirred solution of $5-\mathrm{NO}_{2}-\mathrm{salH}(162.0 \mathrm{mg}, 0.97 \mathrm{mmol})$ in $\mathrm{MeOH}(10 \mathrm{~mL})$. The mixture was stirred at room temperature for $1 \mathrm{~h}$ when $(1 R, 2 R)-(+)$-dpen $(206.0 \mathrm{mg}, 0.97 \mathrm{mmol})$ was added with the concomitant precipitation of $\mathbf{1}^{\prime} \mathbf{b}^{\prime}$ as a violet solid, which was collected after $3 \mathrm{~h}$ under stirring, washed with $\mathrm{MeOH}$ and $i \mathrm{Pr}_{2} \mathrm{O}$, and dried under vacuum (275.0 mg, 52\%). ESI-MS (MeOH): $\mathrm{m} / z 441$ $\left(\left[\mathrm{Cu}\left(\mathrm{L}^{\mathrm{b}}\right)\left(\mathrm{H}_{2} \mathrm{O}\right)\right]^{+}, 100 \%\right)$. Elemental analysis calcd (\%) for $\mathrm{C}_{21} \mathrm{H}_{20} \mathrm{ClCuN}_{3} \mathrm{O}_{7} \cdot \frac{1}{2} \mathrm{H}_{2} \mathrm{O}$ (550.41): C, 45.83; $\mathrm{H}, 3.85$; N, 7.63. Found: $\mathrm{C}, 45.80 ; \mathrm{H}, 4.23$; N, 7.52. FT-IR (KBr): $v\left(\mathrm{NH}_{2}\right) 3315,3259, v\left(\mathrm{H}_{2} \mathrm{O}\right) 3296, v(\mathrm{C}=\mathrm{N})$ $1626,1604, v\left(\mathrm{NO}_{2}\right) 1333, v\left(\mathrm{ClO}_{4}\right) 1082 \mathrm{~cm}^{-1}$.

Starting from an aqueous solution $(3 \mathrm{~mL})$ of $\mathrm{Cu}\left(\mathrm{ClO}_{4}\right)_{2} 6 \mathrm{H}_{2} \mathrm{O}(440.0 \mathrm{mg}, 1.20 \mathrm{mmol})$, py $(290 \mu \mathrm{L}$, $3.60 \mathrm{mmol}), 5-\mathrm{NO}_{2}$-salH $(200.0 \mathrm{mg}, 1.20 \mathrm{mmol})$ in $\mathrm{MeOH}(15 \mathrm{~mL})$, and $(1 R, 2 R)-(+)$-dpen $(255.0 \mathrm{mg}$, $1.20 \mathrm{mmol})$, after $3 \mathrm{~h}$ under stirring, an excess of pyridine $(1 \mathrm{~mL})$ was added and the mixture was further stirred at room temperature for two days, until all $\mathbf{1} \mathbf{b}^{\prime}$ disappeared. The green solution was left aside to slow evaporation for one week, yielding $\mathbf{1 b}$ as a dark green solid that was filtered, washed with $\mathrm{MeOH}$ and $i \mathrm{Pr}_{2} \mathrm{O}$, and dried under vacuum $(540 \mathrm{mg}, 75 \%)$. ESI-MS $(\mathrm{MeOH}): \mathrm{m} / z 455\left(\left[\mathrm{Cu}\left(\mathrm{L}^{\mathrm{b}}\right)(\mathrm{MeOH})\right]^{+}, 60 \%\right)$, $909\left(\left[\mathrm{Cu}_{2}\left(\mathrm{~L}^{\mathrm{b}}\right)_{2}(\mathrm{MeOH})_{2}-\mathrm{H}\right]^{+}\right.$, 100). Elemental analysis calcd (\%) for $\mathrm{C}_{26} \mathrm{H}_{23} \mathrm{ClCuN}_{4} \mathrm{O}_{7}$ (602.47): $\mathrm{C}$, 51.83; H, 3.85; N, 9.30. Found: C, 51.80; $\mathrm{H}, 4.30 ; \mathrm{N}, 9.01$. FT-IR $(\mathrm{KBr}): v\left(\mathrm{NH}_{2}\right) 3318,3269, v(\mathrm{C}=\mathrm{N}) 1645$, $1608, v\left(\mathrm{NO}_{2}\right) 1315, v\left(\mathrm{ClO}_{4}\right) 1098 \mathrm{~cm}^{-1}$.

\subsection{Synthesis of $\left[\mathrm{Cu}\left(\mathrm{L}^{\mathrm{c}}\right)(\mathrm{py})\right]\left(\mathrm{ClO}_{4}\right)(\mathbf{1 c})$}

An aqueous solution $(2 \mathrm{~mL})$ of $\mathrm{Cu}\left(\mathrm{ClO}_{4}\right)_{2} 6 \mathrm{H}_{2} \mathrm{O}(385.4 \mathrm{mg}, 1.05 \mathrm{mmol})$ and py $(170 \mu \mathrm{L}, 2.10 \mathrm{mmol})$ was added to a stirred solution of $5-\mathrm{NO}_{2}-\mathrm{salH}(175.2 \mathrm{mg}, 1.05 \mathrm{mmol})$ in $\mathrm{MeOH}(10 \mathrm{~mL})$. The mixture was stirred at room temperature for $1 \mathrm{~h}$ when $(1 S, 2 S)-(+)-c h x n(118.0 \mathrm{mg}, 1.05 \mathrm{mmol})$ was added, and the mixture was left under stirring for $3 \mathrm{~h}$. The title compound was collected as a violet solid by filtration, washed with $\mathrm{MeOH}$ and $i \operatorname{Pr}_{2} \mathrm{O}$, and dried under vacuum $(320.5 \mathrm{mg}, 63 \%)$. ESI-MS (MeOH): $m / z 325\left(\left[\mathrm{Cu}\left(\mathrm{L}^{\mathrm{c}}\right)\right]^{+}, 20 \%\right), 357\left(\left[\mathrm{Cu}\left(\mathrm{L}^{\mathrm{c}}\right)(\mathrm{MeOH})\right]^{+}, 100\right)$. Elemental analysis calcd $(\%)$ for $\mathrm{C}_{18} \mathrm{H}_{21} \mathrm{ClCuN}_{4} \mathrm{O}_{7}$ (504.39): C, 42.86; H, 4.20; N, 11.11. Found: C, 42.97; H, 4.40; N, 10.90. FT-IR (KBr): $v\left(\mathrm{NH}_{2}\right) 3300,3248, v(\mathrm{C}=\mathrm{N}) 1647,1604, v\left(\mathrm{NO}_{2}\right) 1315, v\left(\mathrm{ClO}_{4}\right) 1104 \mathrm{~cm}^{-1}$.

\subsection{Synthesis of $\left[\mathrm{Cu}\left(5-\mathrm{NO}_{2}-5^{\prime}-\mathrm{H}\right.\right.$-sal-(1R,2R)-dpen] (2a)}

$\mathrm{salH}(37.6 \mathrm{mg}, 0.31 \mathrm{mmol})$ and $\mathrm{NaOH}\left(0.45 \mathrm{~mL}\right.$ of a $0.64 \mathrm{~mol} \mathrm{~L}^{-1}$ aqueous solution, $\left.0.29 \mathrm{mmol}\right)$ were added to a solution of $\mathbf{1 b}(142.4 \mathrm{mg}, 0.24 \mathrm{mmol})$ in $\mathrm{MeOH}(10 \mathrm{~mL})$, and the reaction mixture was refluxed for $1 \mathrm{~h}$. The resulting violet solid was filtered, washed with $\mathrm{MeOH}$ and $i \operatorname{Pr}_{2} \mathrm{O}$, and dried under vacuum (95.1 mg, 77\%). ESI-MS (MeOH): $\mathrm{m} / z 527\left([\mathrm{M}+1]^{+}, 10 \%\right), 1053\left([2 \mathrm{M}+1]^{+}, 35\right), 1075$ $\left([2 \mathrm{M}+\mathrm{Na}]^{+}\right.$, 100). Elemental analysis calcd (\%) for $\mathrm{C}_{28} \mathrm{H}_{21} \mathrm{CuN}_{3} \mathrm{O}_{4}$ (527.04): C, 63.81; H, 4.02; N, 7.97 . Found: $\mathrm{C}, 63.94 ; \mathrm{H}, 4.41 ; \mathrm{N}, 8.02$. FT-IR $(\mathrm{KBr}): v(\mathrm{C}=\mathrm{N}) 1632,1604, v\left(\mathrm{NO}_{2}\right) 1314 \mathrm{~cm}^{-1}$.

\subsection{Synthesis of [Cu(5-NO2- ${ }^{\prime}-\mathrm{OMe}$-sal-(1R,2R)-dpen] (2b)}

5-OMe-salH $(41.0 \mathrm{mg}, 0.27 \mathrm{mmol})$ and $\mathrm{NaOH}\left(0.35 \mathrm{~mL}\right.$ of a $0.76 \mathrm{~mol} \mathrm{~L}^{-1}$ aqueous solution, $0.27 \mathrm{mmol})$ were added to a solution of $\mathbf{1 b}(133.2 \mathrm{mg}, 0.22 \mathrm{mmol})$ in $\mathrm{MeOH}(10 \mathrm{~mL})$, and the reaction mixture was refluxed for $30 \mathrm{~min}$. The resulting military green solid was filtered, washed with $\mathrm{MeOH}$ and $i \operatorname{Pr}_{2} \mathrm{O}$, and dried under vacuum (110.2 mg, 92\%). ESI-MS (MeOH): $m / z 557\left([\mathrm{M}+1]^{+}, 25 \%\right), 1113$ $\left([2 \mathrm{M}+1]^{+}, 60\right), 1135\left([2 \mathrm{M}+\mathrm{Na}]^{+}, 100\right)$. Elemental analysis calcd (\%) for $\mathrm{C}_{29} \mathrm{H}_{23} \mathrm{CuN}_{3} \mathrm{O}_{5}(557.06)$ : C, 62.53; H, 4.16; N, 7.54. Found: $\mathrm{C}, 62.56 ; \mathrm{H}, 4.67 ; \mathrm{N}, 7.28$. FT-IR $(\mathrm{KBr}): v(\mathrm{C}=\mathrm{N}) 1634,1603, v\left(\mathrm{NO}_{2}\right)$ $1313 \mathrm{~cm}^{-1}$.

\subsection{Synthesis of $\left[\mathrm{Cu}\left(5-\mathrm{NO}_{2}-5^{\prime}-\mathrm{OMe}-\mathrm{sal}-(1 \mathrm{~S}, 2 \mathrm{~S})-\mathrm{ch} x n\right](2 \mathrm{c})\right.$}

5-OMe-salH $(46.2 \mathrm{mg}, 0.30 \mathrm{mmol})$ and $\mathrm{NaOH}\left(0.40 \mathrm{~mL}\right.$ of a $0.76 \mathrm{~mol} \mathrm{~L}^{-1}$ aqueous solution, $0.30 \mathrm{mmol})$ were added to a solution of $1 \mathrm{c}(128.3 \mathrm{mg}, 0.26 \mathrm{mmol})$ in $\mathrm{MeOH}(10 \mathrm{~mL})$, and the reaction 
mixture was refluxed for $30 \mathrm{~min}$. The resulting dark green solid was filtered, washed with $\mathrm{MeOH}$ and $i \mathrm{Pr}_{2} \mathrm{O}$, and dried under vacuum (70.1 mg, 59\%). ESI-MS (MeOH): $\mathrm{m} / z 459\left([\mathrm{M}+1]^{+}, 55 \%\right), 481$ $\left([\mathrm{M}+\mathrm{Na}]^{+}, 15\right), 939\left([2 \mathrm{M}+\mathrm{Na}]^{+}, 100\right)$. Elemental analysis calcd (\%) for $\mathrm{C}_{21} \mathrm{H}_{21} \mathrm{CuN}_{3} \mathrm{O}_{5}(458.96): \mathrm{C}$, 54.96; H, 4.61; N, 9.16. Found: C, 54.57; H, 5.02; N, 8.84. FT-IR (KBr): $v(\mathrm{C}=\mathrm{N}) 1635,1600, v\left(\mathrm{NO}_{2}\right)$ $1316 \mathrm{~cm}^{-1}$.

\subsection{X-ray Data Collection and Structure Determination}

Crystals suitable for X-ray diffraction (XRD) experiments were obtained directly by slow evaporation of the $\mathrm{MeOH}$ reaction mixture for $\mathbf{1 a}$ and $\mathbf{1} \mathbf{b}$, and by diffusion of $n$-hexane into an acetone solution for 1c. Crystal data and details of data collection are summarized in Table 1. Intensity data for 1a were collected on the XRD1 beamline of the Elettra Synchrotron Light Laboratory (Trieste, Italy), using radiation $\lambda=0.8 \AA$, owing to the very small dimensions of the crystals. For $\mathbf{1 b}$ and $\mathbf{1 c}$, data collection was performed on a Bruker Apex II diffractometer (Bruker AXS Inc., Madison, WI, USA) using graphite monochromatic Mo-K $\alpha$ radiation $(\lambda=0.71073 \AA)$.

Table 1. Crystallographic data for $\mathbf{1 a} \cdot 0.5 \mathrm{H}_{2} \mathrm{O}, \mathbf{1 b}$, and $\mathbf{1 c}$.

\begin{tabular}{|c|c|c|c|}
\hline & $1 \mathrm{a} \cdot 0.5 \mathrm{H}_{2} \mathrm{O}$ & $1 b$ & 1c \\
\hline \multicolumn{4}{|l|}{ Crystal Data } \\
\hline Moiety formula & {$\left[\mathrm{C}_{26} \mathrm{H}_{23} \mathrm{CuN}_{4} \mathrm{O}_{3}\right]\left(\mathrm{ClO}_{4}\right) \cdot 0.5 \mathrm{H}_{2} \mathrm{O}$} & {$\left[\mathrm{C}_{26} \mathrm{H}_{23} \mathrm{CuN}_{4} \mathrm{O}_{3}\right]\left(\mathrm{ClO}_{4}\right)$} & {$\left[\mathrm{C}_{18} \mathrm{H}_{21} \mathrm{CuN}_{4} \mathrm{O}_{3}\right]\left(\mathrm{ClO}_{4}\right)$} \\
\hline Sum formula & $\mathrm{C}_{26} \mathrm{H}_{24} \mathrm{ClCuN}_{4} \mathrm{O}_{7.5}$ & $\mathrm{C}_{26} \mathrm{H}_{23} \mathrm{ClCuN}_{4} \mathrm{O}_{7}$ & $\mathrm{C}_{18} \mathrm{H}_{21} \mathrm{ClCuN}_{4} \mathrm{O}_{7}$ \\
\hline$M$ & 611.47 & 602.47 & 504.38 \\
\hline Crystal system & monoclinic & orthorhombic & tetragonal \\
\hline Space group & $P 2_{1} / n$ (n. 14) & $P 2{ }_{1}{ }_{1} 2_{1}$ (n. 19) & $P 4_{3}$ (n. 78) \\
\hline$a / \AA$ & $13.232(3)$ & $7.1810(7)$ & $11.6613(6)$ \\
\hline$b / \AA$ & $13.329(3)$ & $21.970(2)$ & $11.6613(6)$ \\
\hline$c / \AA$ & $15.383(3)$ & $35.121(3)$ & $15.3217(8)$ \\
\hline$\alpha /^{\circ}$ & 90 & 90 & 90 \\
\hline$\beta /^{\circ}$ & $92.40(3)$ & 90 & 90 \\
\hline$\gamma /^{\circ}$ & 90 & 90 & 90 \\
\hline$V / \AA^{3}, Z$ & $293(2), 4$ & $5541.0(9), 8$ & $2083.5(2), 4$ \\
\hline Reflns for cell det & 130 & 6497 & 9386 \\
\hline $2 \theta /{ }^{\circ}$ for cell det & $16.0-52.0$ & $4.64-40.24$ & $4.39-60.26$ \\
\hline$D_{x} / \mathrm{Mg} \mathrm{m}^{-3}$ & 1.515 & 1.444 & 1.608 \\
\hline$\mu / \mathrm{mm}^{-1}$ & 1.318 & 0.935 & 1.226 \\
\hline Colour, habit & green, needle & violet, needle & red, block \\
\hline Dimensions/mm & $0.20 \times 0.01 \times 0.01$ & $0.58 \times 0.14 \times 0.08$ & $0.36 \times 0.34 \times 0.30$ \\
\hline \multicolumn{4}{|l|}{ Data Collection } \\
\hline Temperature/K & $293(2)$ & 293(2) & $294(2)$ \\
\hline radiation $\lambda / \AA$ & synchrotron, 0.800 & Мo-K $\alpha, 0.71073$ & $\mathrm{Mo}-\mathrm{K} \alpha, 0.71073$ \\
\hline Scan type & $\varphi$ & $\varphi$ and $\omega$ & $\varphi$ and $\omega$ \\
\hline $2 \theta_{\max } /^{\circ}$ & 57.4 & 49.7 & 64.5 \\
\hline$h$ range & $-16 \rightarrow 16$ & $-8 \rightarrow 8$ & $-17 \rightarrow 17$ \\
\hline$k$ range & $-17 \rightarrow 17$ & $-25 \rightarrow 25$ & $-17 \rightarrow 17$ \\
\hline$l$ range & $-17 \rightarrow 17$ & $-41 \rightarrow 41$ & $-22 \rightarrow 22$ \\
\hline Intensity decay & None & None & None \\
\hline Measured reflns & 31,811 & 66,969 & 44,359 \\
\hline Independent reflns & 4628 & 9600 & 7153 \\
\hline Reflns with $I>2 \sigma(I)$ & 4001 & 7633 & 6226 \\
\hline$R_{\text {int }}$ & 0.0390 & 0.0415 & 0.0214 \\
\hline \multicolumn{4}{|l|}{ Refinement on $F^{2}$} \\
\hline$R_{1}, w R_{2}\left[F^{2}>2 \sigma\left(F^{2}\right)\right]$ & $0.0429,0.1165$ & $0.0430,0.1073$ & $0.0321,0.0901$ \\
\hline$R_{1}, w R_{2}$ [all data] & $0.0499,0.1231$ & $0.0604,0.1176$ & $0.0394,0.0949$ \\
\hline$S$ & 1.101 & 1.016 & 1.029 \\
\hline Flack parameter & & $0.007(5)$ & $0.014(3)$ \\
\hline Params, restraints & 455,159 & 703,0 & 280,1 \\
\hline$(\Delta / \sigma)_{\max }$ & 0.001 & 0.001 & 0.001 \\
\hline$\Delta \rho_{\max }, \Delta \rho_{\min } / \mathrm{e} \AA^{-3}$ & $0.293,-0.343$ & $0.375,-0.288$ & $0.396,-0.345$ \\
\hline
\end{tabular}


During data collections, no crystal decay was observed, so no time-decay correction was needed. Data reductions were performed with MOSFLM version 6.11c [66] and SCALA [67] (for 1a) and with SAINT and SADABS [68] (for $\mathbf{1 b}$ and 1c). All the structures were solved by direct methods and refined with SHELXL-2016/6 [69] implemented in WinGX-Version 2014.1 system [70]. The program Mercury was used for graphics [71]. Anisotropic thermal parameters were used for all non-hydrogen atoms. The isotropic thermal parameters of $\mathrm{H}$ atoms were fixed at 1.2 (1.5 for methylene groups) times those of the atom to which they were attached. All $\mathrm{H}$ atoms were placed in calculated positions and refined by a riding model.

CCDC 1954460-1954462 contains the supplementary crystallographic data for 1a-c, respectively. These data can be obtained free of charge via http://www.ccdc.cam.ac.uk/conts/retrieving.html, or from the Cambridge Crystallographic Data Centre, 12 Union Road, Cambridge CB2 1EZ, UK; fax: (+44) 1223-336-033, or e-mail: deposit@ccdc.cam.ac.uk.

\subsection{Computational Details}

Geometry optimizations of the cations $\left[\mathrm{Cu}\left(\mathrm{L}^{\mathrm{a}-\mathrm{c}}\right)(\mathrm{py})\right]^{+}$of $\mathbf{1 a - c}$ and of $\mathbf{2 a - c}$ were performed at $\mathrm{UM} 06 / 6-311++G(d, p)$ level of theory. For $1 \mathbf{a}-\mathbf{c}$, the respective single crystal X-ray structures were used as a starting point, while for $\mathbf{2 a - c}$, the initial guess for optimization was build up from the optimized geometries of $\mathbf{1} \mathbf{b}$ and $\mathbf{1} \mathbf{c}$ with the proper substitutions. SHG hyperpolarizabilities, that is, the $\beta(-2 \omega ; \omega, \omega)$ tensors, were computed in $\mathrm{CHCl}_{3}$ within the coupled perturbed Kohn-Sham (CPKS) approach, at the same frequency as used as in the Kurtz-Perry experiments. The CAM-B3LYP functional [72], which has been recommended for hyperpolarizability calculations of mid-size organic chromophores [73], was adopted. The solvent was described as a continuum dielectric according to the polarizable continuum model in its integral equation formalism variant (IEFPCM algorithm) [74]. A pruned $(99,590)$ grid was selected for computation as well as the use of two-electron integrals and their derivatives. As already pointed out in our previous studies on the NLO properties of [Cu(5-A-5'-D-salen/saltn)] [38] and [Ni(5-A-5'-D-saltn)] [39] complexes, two main and almost orthogonal components of the dipole moment and hyperpolarizability vectors can be singled out in these compounds, one along the largest molecular extension and the other across the $\mathrm{ON}(\mathrm{py}) / \mathrm{O}_{2}$ and $\mathrm{N}_{2}$ atoms of the donor set of compounds $\mathbf{1}$ and 2 . In order to meaningfully compare these components among the examined compounds, a common reference frame was adopted, whereby the origin coincides with the copper ion, the $x$ axis passes through $\mathrm{C} 4$ (the carbon atom of the six-membered chelate ring on the acceptor side) and points from the acceptor towards the donor group, the $y$ axis lies in the $\mathrm{N}_{3} \mathrm{O} / \mathrm{N}_{2} \mathrm{O}_{2}$ plane and points from the $\mathrm{ON}(\mathrm{py}) / \mathrm{O}_{2}$ towards the $\mathrm{N}_{2}$ atoms of the donor set, and the $z$ axis completes the right-handed reference system. This frame strictly recalls that adopted for the [Cu(5-A-5'-D-salen/saltn)] [38] and [Ni(5-A-5'-D-saltn)] [39] complexes.

\subsection{Kurtz-Perry Powder Measurements}

The measurements of SHG intensity were carried out by the Kurtz-Perry powder technique [47] using a nanosecond Nd:YAG pulsed $(10 \mathrm{~Hz})$ laser. The fundamental beam $(1.064 \mu \mathrm{m})$ was focused in a hydrogen cell (1 m long, $50 \mathrm{~atm})$ and the outcoming Stokes-shifted radiation generation at $1.907 \mu \mathrm{m}$ was used as the fundamental beam for SHG. The SHG signal coming from capillary tubes containing grinded microcrystalline powders $(50-80 \mu \mathrm{m})$ of the samples was detected by a photomultiplier.

\section{Results and Discussion}

\subsection{Synthesis and IR/MS Characterization}

Even if it is reported that tridentate HL ligands, especially with chxn, can be obtained without the support of a metal ion [56,75], because of our interest in copper(II) derivatives, we decided to directly employ the template method that was revealed to be efficient with aliphatic diamines en and tn [38,76-78], as well as with the aliphatic diamines chxn and dpen. The series of mononuclear derivatives 1a-c with 
tridentate Schiff base ligands was then synthesized by reaction of $\mathrm{NO}_{2}$-salH:Cu$\left(\mathrm{ClO}_{4}\right)_{2}$ :diamine in a 1:1:1 ratio in the presence of excess py acting as the forth ligand, so as to avoid the double condensation on both $\mathrm{NH}_{2}$ groups of chxn and dpen. The cheapest $(1 S, 2 R)$-meso-dpen was initially employed with the aim of studying the best reaction and isolation conditions, and then extending the synthetic protocol to the most expensive optically pure $(1 R, 2 R)-(+)$-dpen and $(1 S, 2 S)-(+)$-chxn. It is curious to note how we could instead observe a moderate different reactivity of $(1 S, 2 R)$-meso-dpen compared with $(1 R, 2 R)-(+)$-dpen. In fact, the species $\left[\mathrm{Cu}\left(\mathrm{L}^{\mathrm{b}}\right)\left(\mathrm{H}_{2} \mathrm{O}\right)\right]\left(\mathrm{ClO}_{4}\right), \mathbf{1}^{\prime}$, could be isolated with $(1 R, 2 R)-(+)$-dpen, where the crystal packing of cations and anions in the solid state seems to confer a lower solubility to the aquo complex with its preferential precipitation. A similar complex with $\mathrm{NO}_{2}$-salH, en and water as the forth coordinated ligand was also isolated by us in our previous work [77]. Only in the presence of a larger excess of pyridine, $\mathbf{1} \mathbf{b}^{\prime}$ was converted into $\mathbf{1 b}$ with coordinated py. Intermediates $\mathbf{1 b}$ and $\mathbf{1} \mathbf{c}$ were then suitably converted to $\mathbf{2 a}$, $\mathbf{2 b}$, and $\mathbf{2} \mathbf{c}$ by condensation with the second carbonyl derivative, salH or 5-OMe-salH, in refluxing $\mathrm{MeOH}$; the latter aldehyde, owing to the donor group, is characterized by a higher reactivity with a consequent lower reaction time (30 $\mathrm{min})$ compared with salH (1 h).

All compounds were characterized by infrared spectroscopy, where the $\mathrm{N}-\mathrm{H}$ stretching bands in the $3350-3250 \mathrm{~cm}^{-1}$ spectral range are diagnostic for the formation of intermediates $\mathbf{1 a - c}$ and $\mathbf{1} \mathbf{b}^{\prime}$. The disappearance of such bands in the condensation reaction to obtain $\mathbf{2 a - c}$ could be used as a probe of the complete conversion of the intermediates to the final tetradentate derivatives. The $\mathrm{C}=\mathrm{N}$ stretching bands are also subjected to peculiar changes on going from $1645-1647 \mathrm{~cm}^{-1}$ in $\mathbf{1 b}$ and $1 \mathrm{c}$ to $1632-1635$ in 2a-c. In all derivatives, the stretching band of the nitro group at about $1315 \mathrm{~cm}^{-1}$ is detectable. The coordinated water molecule in $\mathbf{1} \mathbf{b}^{\prime}$ can be recognized through the narrow $\mathrm{O}-\mathrm{H}$ stretching band at $3296 \mathrm{~cm}^{-1}$ in between the symmetric and asymmetric $\mathrm{NH}_{2}$ bands. Furthermore, the different donating power to copper(II) of the oxygen atom in the water molecule compared with the nitrogen atom of py leads to modifications in the stretching bands of the nitro group, which shifts to $1333 \mathrm{~cm}^{-1}$, and of the $\mathrm{C}=\mathrm{N}$ bond, which moves to $1626 \mathrm{~cm}^{-1}$.

The chemical purity of bulk materials was proved by elemental analyses and all compounds were also subjected to MS-ESI investigations. In particular, mass peaks at $\mathrm{m} / \mathrm{z}$ corresponding to the $\left[\mathrm{Cu}\left(\mathrm{L}^{\mathrm{a}-\mathrm{c}}\right)\right]^{+}$and solvated $\left[\mathrm{Cu}\left(\mathrm{L}^{\mathrm{a}-\mathrm{c}}\right)(\mathrm{MeOH})\right]^{+}$fragments could be detected for $\mathbf{1 a}, \mathbf{1} \mathbf{b}$, and $\mathbf{1 c}$, while the most intense peak of $\mathbf{1 b}^{\prime}$ was the $\left[\mathrm{Cu}\left(\mathrm{L}^{\mathrm{b}}\right)\left(\mathrm{H}_{2} \mathrm{O}\right)\right]^{+}$ion, suggesting a rather strong $\mathrm{Cu}-\mathrm{O}$ (water) bond. In the case of $\mathbf{2 a}, \mathbf{2} \mathbf{b}$, and $\mathbf{2} \mathbf{c}$, mass peaks at $m / z$ corresponding to $[\mathrm{M}+1]^{+}$and $[\mathrm{M}+\mathrm{Na}]^{+}$species, together with the dimeric $[2 \mathrm{M}+1]^{+}$and $[2 \mathrm{M}+\mathrm{Na}]^{+}$ions, were observed. It is not uncommon to observe such dimeric signals in tetradentate Schiff base metal complexes owing to the establishment of short intermolecular $\mathrm{M} \cdots \mathrm{O}$ (phenol) interactions [33], especially with copper(II) and its tendency to weakly interact with a fifth donor atom $[38,77]$.

\subsection{X-ray Structures of $1 a \cdot 0.5 \mathrm{H}_{2} \mathrm{O}, \mathbf{1} \boldsymbol{b}$, and $1 c$}

Single crystals suitable for XRD experiments were obtained for $\mathbf{1 a} \cdot 0.5 \mathrm{H}_{2} \mathrm{O}, \mathbf{1} \mathbf{b}$, and $\mathbf{1}$ c bearing the tridentate Schiff base ligands $\mathrm{L}^{-}$. The molecular structures of $\mathbf{1 b}$ and $\mathbf{1 c}$ are reported in Figure 1 , while a fragment of the crystal packing of 1a is depicted in Figure S3 in SM with an atom numbering scheme. Selected bond distances, angles, and other structural parameters of all compounds helpful for the discussion are reported in Table 2. Compound 1a crystallizes in the centrosymmetric $P 2_{1} / n$ space group, because $(1 S, 2 R)$-meso-dpen can condense the amino group with $\mathrm{NO}_{2}$-salH on either the $R$ or $S$ chiral side, and this gives rise to two enantiomeric complexes, both present in the unit cell and related by the inversion center. When moving to $(1 R, 2 R)-(+)$-dpen and $(1 S, 2 S)-(+)-$ chxn, only one pure enantiomer is present, so that $\mathbf{1} \mathbf{b}$ and $\mathbf{1} \mathbf{c}$ crystallize in the orthorhombic $P 2{ }_{1} 2_{1} 2_{1}$ and the chiral tetragonal $P 4_{3}$ space groups, respectively. 


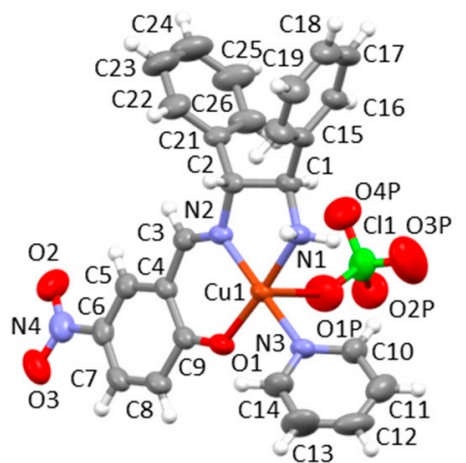

(a)

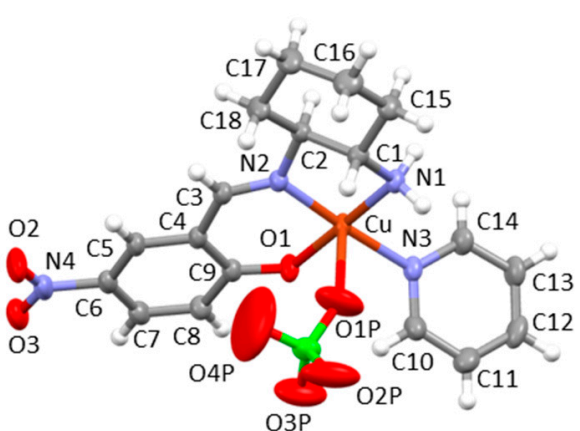

(b)

Figure 1. X-ray structures with atom numbering scheme of (a) one of the two independent cations of $\mathbf{1 b}$ with one interacting perchlorate anion and (b) 1c. Displacement ellipsoids are drawn at $30 \%$ probability; color code: $\mathrm{Cu}=$ orange, $\mathrm{Cl}=$ green, $\mathrm{O}=$ red, $\mathrm{N}=$ light blue, $\mathrm{C}=$ grey, $\mathrm{H}=$ white.

Table 2. Selected interatomic distances $(\AA)$ and angles $\left({ }^{\circ}\right)$, intermolecular contacts $(\AA)$, and selected parameters in $\mathbf{1 a} \cdot 0.5 \mathrm{H}_{2} \mathrm{O}, \mathbf{1} \mathbf{b}$, and $\mathbf{1 c}$ from single crystal XRD (first line) and UM06/6-311++G(d,p) calculations on cations (second line, in italics; see Figure 1 and Figure S3 in SM for atom labelling).

\begin{tabular}{|c|c|c|c|}
\hline & $1 \mathrm{a} \cdot 0.5 \mathrm{H}_{2} \mathrm{O}$ & $1 b$ & $1 \mathrm{c}$ \\
\hline \multirow[t]{2}{*}{$\mathrm{Cu} 1-\mathrm{N} 1 / \mathrm{Cu} 2-\mathrm{N} 5^{1}$} & $2.011(5)$ & $1.998(4) / 2.002(5)^{1}$ & $2.007(2)$ \\
\hline & 2.066 & 2.054 & 2.060 \\
\hline \multirow[t]{2}{*}{$\mathrm{Cu} 1-\mathrm{N} 2 / \mathrm{Cu} 2-\mathrm{N} 6^{1}$} & $1.949(4)$ & $1.958(4) / 1.951(4)^{1}$ & $1.951(2)$ \\
\hline & 1.940 & 1.948 & 1.952 \\
\hline \multirow[t]{2}{*}{$\mathrm{Cu} 1-\mathrm{O} 1 / \mathrm{Cu} 2-\mathrm{O} 4^{1}$} & $1.903(4)$ & $1.901(4) / 1.873(4)^{1}$ & $1.902(2)$ \\
\hline & 1.899 & 1.896 & 1.894 \\
\hline \multirow[t]{2}{*}{$\mathrm{Cu} 1-\mathrm{N} 3 / \mathrm{Cu} 2-\mathrm{N}^{1}{ }^{1}$} & $1.994(5)$ & $2.011(5) / 2.032(5)^{1}$ & $2.015(2)$ \\
\hline & 2.014 & 2.030 & 2.028 \\
\hline $\mathrm{Cu} 1 \cdots \mathrm{O} 1 \mathrm{p}, \mathrm{Cu} 1 \cdots \mathrm{O} 2 \mathrm{p}^{2}$ & 2.59(1), absent & $2.418(5), 2.557(5)^{2}$ & $2.654(5), 2.857(5)$ \\
\hline \multirow[t]{2}{*}{ N1-Cu1-N2/N5-Cu2-N6 ${ }^{1}$} & $83.38(18)$ & $83.43(18) / 83.27(18)^{1}$ & $84.36(9)$ \\
\hline & 83.44 & 83.35 & 83.49 \\
\hline \multirow[t]{2}{*}{ N2-Cu1-O1/N6-Cu2-O4 ${ }^{1}$} & $92.65(17)$ & $93.60(18) / 92.27(18)^{1}$ & $93.58(9)$ \\
\hline & 93.31 & 93.52 & 93.84 \\
\hline \multirow[t]{2}{*}{$\mathrm{O} 1-\mathrm{Cu} 1-\mathrm{N} 3 / \mathrm{O} 4-\mathrm{Cu} 2-\mathrm{N} 7^{1}$} & $87.86(18)$ & $89.25(18) / 88.9(2)^{1}$ & 91.02(9) \\
\hline & 89.84 & 88.45 & 88.76 \\
\hline \multirow[t]{2}{*}{ N3-Cu1-N1/N7-Cu2-N5 ${ }^{1}$} & $96.19(19)$ & $93.46(19) / 96.2(2)^{1}$ & $91.02(10)$ \\
\hline & 95.29 & 94.69 & 94.44 \\
\hline \multirow[t]{2}{*}{ N1-Cu1-O1/N5-Cu2-O4 ${ }^{1}$} & $173.86(18)$ & $175.0(2) / 172.8(2)^{1}$ & $177.24(10)$ \\
\hline & 168.50 & 175.78 & 171.61 \\
\hline \multirow[t]{2}{*}{ N2-Cu1-N3/N6-Cu2-N7 ${ }^{1}$} & $178.8(2)$ & $175.3(2) / 174.0(2)^{1}$ & $175.36(9)$ \\
\hline & 169.69 & 178.02 & 175.51 \\
\hline \multirow[t]{2}{*}{$\mathrm{Cu} 1 \cdots \mathrm{N}_{3} \mathrm{O} / \mathrm{Cu} 2 \cdots \mathrm{N}_{3} \mathrm{O}(\AA)^{1}$} & 0.030 & $0.066 / 0.006^{1}$ & 0.020 \\
\hline & 0.005 & 0.022 & 0.034 \\
\hline \multirow[t]{2}{*}{$\mathrm{N}_{3} \mathrm{O} \angle \mathrm{py}\left({ }^{\circ}\right)$} & $63.0(1)$ & $54.2(3) / 14.1(1)^{1}$ & $58.5(1)$ \\
\hline & 41.27 & 36.54 & 38.86 \\
\hline
\end{tabular}

${ }^{1}$ the second set of atom names and parameters are referred to the second independent molecule of $\mathbf{1} \mathbf{b} ;{ }^{2}$ the $\mathrm{Cu} 2$ atom in $\mathbf{1 b}$ is not involved in short intermolecular contacts with perchlorate anions.

All complexes show the expected square-planar geometry around the copper(II) atoms, where the basal plane is formed by the $\mathrm{N}_{2} \mathrm{O}$ set of donors from the $\mathrm{L}^{\mathrm{a}-}, \mathrm{L}^{\mathrm{b}-}$, and $\mathrm{L}^{\mathrm{c}-}$ ligands for $\mathbf{1 a}, \mathbf{1} \mathbf{b}$, 
and 1c, respectively, and the fourth position is occupied by the nitrogen atom of the pyridine ligand. All complexes are characterized by very slight tetrahedral distortion of the donor set, as indicated by the values of the O1-N2-N1-N3 torsion angles, all less than $1.0^{\circ}$, except for the second molecule of the asymmetric unit of $\mathbf{1 b}$, where the O4-N6-N5-N4 torsion angle measures $7.9^{\circ}$. The displacement of the copper(II) ions from the $\mathrm{N}_{3} \mathrm{O}$ l.s. planes is very low in all cases $(<0.07 \AA)$. Coordination distances and angles are comparable to those of other copper compounds with $\mathrm{N}_{2} \mathrm{O}$ tridentate Schiff base ligands and pyridine as the forth ancillary ligand $[77,79]$.

The asymmetric units of $\mathbf{1 a}$ and $1 \mathrm{c}$ comprise one independent $\left[\mathrm{Cu}\left(\mathrm{L}^{\mathrm{a} / \mathrm{c}}\right)(\mathrm{py})\right]^{+}$cation and $\mathrm{ClO}_{4}{ }^{-}$ anion, together with a co-crystallized half molecule of water in the case of 1a. Analysis of the crystal structure of 1a reveals that the perchlorate anion is disordered over three positions: a majority one (labelled with R, Figure S3a in SM), which is placed far from the metal and is hydrogen-bonded to one iminic hydrogen atom $\left(\mathrm{N} 1-\mathrm{H} 1 \mathrm{~B} \cdots \mathrm{O} 3 \mathrm{R}, \mathrm{r}_{\mathrm{H} \cdots \mathrm{O}}=2.29 \AA, \mathrm{NH} \cdots \mathrm{O}\right.$ angle $\left.=138.1^{\circ}\right)$ and a $\mathrm{CH}$ group of the sal moiety $\left(\mathrm{C} 3-\mathrm{H} 3 \cdots \mathrm{O} 2 \mathrm{R}, \mathrm{r}_{\mathrm{H} \cdots \mathrm{O}}=2.59 \AA, \mathrm{CH} \cdots \mathrm{O}\right.$ angle $\left.=156.5^{\circ}\right)$; and a minority one, which is in turn disordered over two almost overlapped positions (labelled as $\mathrm{P}$ and Q) with equal occupancy, one of them weakly interacting with copper $(\mathrm{Cu} 1 \cdots \mathrm{O} 1 \mathrm{P}=2.586 \AA$, Figure $\mathrm{S} 3 \mathrm{~b}$ in $\mathrm{SM})$. The water molecule is complementary to the perchlorate anion: when the most populated $\mathrm{ClO}_{4}{ }^{-}$site is occupied, the oxygen atom is placed at $\mathrm{Cu} 1 \cdots \mathrm{O} 1 \mathrm{~W}=2.57(1) \AA$ from copper and is hydrogen-bonded, on the other side, with $\mathrm{ClO}_{4}{ }^{-}\left(\mathrm{r}_{\mathrm{O} 1 \mathrm{~W} \cdots \mathrm{O} 1 \mathrm{R}}=2.854 \AA\right.$ ); otherwise, it is hydrogen-bonded to the iminic hydrogen atom $\left(\mathrm{N} 1-\mathrm{H} 1 \mathrm{~B} \cdots \mathrm{O} 2 \mathrm{~W}, \mathrm{r}_{\mathrm{H} \cdots \mathrm{O}}=2.18 \AA\right.$, $\mathrm{NH} \cdots \mathrm{O}$ angle $\left.=152.6^{\circ}\right)$.

The asymmetric unit of $\mathbf{1 b}$ contains two independent $\left[\mathrm{Cu}\left(\mathrm{L}^{\mathrm{b}}\right)(\mathrm{py})\right]\left(\mathrm{ClO}_{4}\right)$ ionic pairs. In one of them (Cu1), the pyridine ring is twisted with respect to the coordination plane $\left(54.2(3)^{\circ}\right)$, as also observed in 1a $\left(63.0(1)^{\circ}\right)$ and 1c $\left(58.5(1)^{\circ}\right)$. Short intermolecular contacts are observed between the copper ion and perchlorate anions on both sides of the coordination plane (Cu1 $\cdots \mathrm{O} 1 \mathrm{p}=2.418(5)$ and $\mathrm{Cu} 1 \cdots \mathrm{O} 2 \mathrm{p}^{\prime}=2.557(5) \AA$ ), forming linear $1 \mathrm{D}$ chains $\cdots \mathrm{Cu} 1 \cdots \mathrm{O} 1 \mathrm{p}-\mathrm{Cl}-\mathrm{O} 2 \mathrm{p} \cdots \mathrm{Cu} 1^{\prime} \cdots$ along the crystallographic $a$ axis (chain A). The second independent cation (Cu2) shows a lower rotation of the pyridine with respect to the coordination plane $\left(14.1(1)^{\circ}\right)$, in absence of short $\mathrm{Cu} \cdots \mathrm{OClO}_{3}$ contacts, while the perchlorate anion is involved in rather strong hydrogen bonds with the coordinated amino

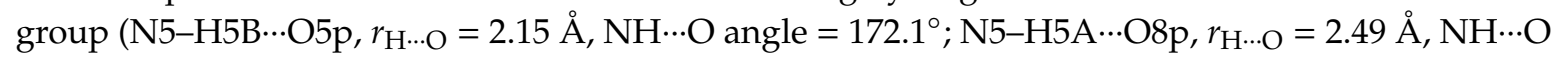
angle $=158.6^{\circ}$, yielding a second supramolecular $1 \mathrm{D}$ alignment (chain $\mathrm{B}$ ). The two chains are then inserted one in the other with weak $\mathrm{C}-\mathrm{H} \cdots \mathrm{O}$ hydrogen bonds connecting aromatic units of one chain with either the nitro moiety or the perchlorate anion of the adjacent chain (Figure 2a). The angle between coordination 1.s. planes of $\mathrm{Cu} 1$ and $\mathrm{Cu} 2$ is equal to $9.26^{\circ}$. Most importantly, in view of the analysis of the NLO response, cations are iso-oriented along each chain, according to a head-to-head arrangement, while stacked cations between $\mathrm{A}$ and $\mathrm{B}$ chains are rotated by about $90^{\circ}$ with respect to the each other (see Figure 2b).

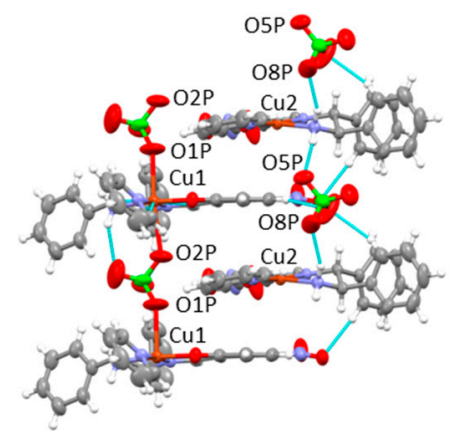

(a)

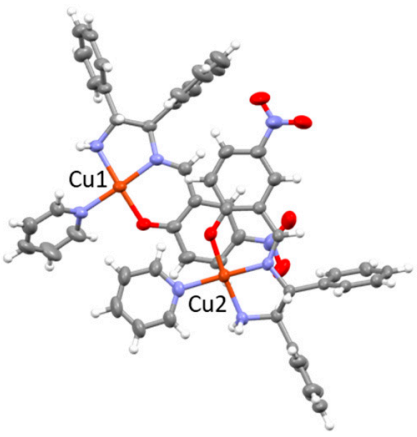

(b)

Figure 2. Fragments of crystal packing in $\mathbf{1 b}$ viewed along (a) $c$ and (b) $a$; displacement ellipsoids are drawn at $30 \%$ probability; color code: $\mathrm{Cu}=$ orange, $\mathrm{Cl}=$ green, $\mathrm{O}=$ red, $\mathrm{N}=$ light blue, $\mathrm{C}=$ grey, $\mathrm{H}=$ white (intermolecular contacts are shown as cyan lines; perchlorate anions are not shown in (b) for clarity). 
Short contacts with the perchlorate anions on both sides of the coordination plane can also be detected in 1c $(\mathrm{Cu} 1 \cdots \mathrm{O} 1 \mathrm{p}=2.654(5) \AA, \mathrm{Cu} 1 \cdots \mathrm{O} 2 \mathrm{p}=2.857(5) \AA)$, even if slightly longer than in $\mathbf{1 b}$, thus producing a zig-zag 1D chain along the crystallographic $c$ axis with an angle between three consecutive copper(II) ions of $159.1^{\circ}$ (Figure 3a). Along this direction, cations are almost parallel (the angle between the coordination 1.s. planes of two consecutive cations measures $16.94^{\circ}$ ) and oriented in the opposite direction (see Figure 3b), suggesting a detrimental effect on the NLO response in the crystal phase. The amino group in $\mathbf{1} \mathbf{c}$ is involved in a short hydrogen bond with the nitro group of an adjacent molecule $\left(\mathrm{N} 1-\mathrm{H} 1 \mathrm{~A} \cdots \mathrm{O}^{\prime}, \mathrm{r}_{\mathrm{H} \cdots \mathrm{O}^{\prime}}=2.28 \AA, \mathrm{NH} \cdots \mathrm{O}^{\prime}\right.$ angle $\left.=157.9^{\circ}\right)$, which is further engaged in short contacts with the pyridine ring $\left(\mathrm{O}^{\prime} \cdots \mathrm{C} 13=3.203(5) \AA, \mathrm{O}^{\prime} \cdots \mathrm{C} 14=3.155(4) \AA\right)$, giving rise to the inter-locked mode between parallel chains. This arrangement forms 2D layers parallel to the $a b$ plane, where the molecules of each layer are alternately oriented in the same direction.

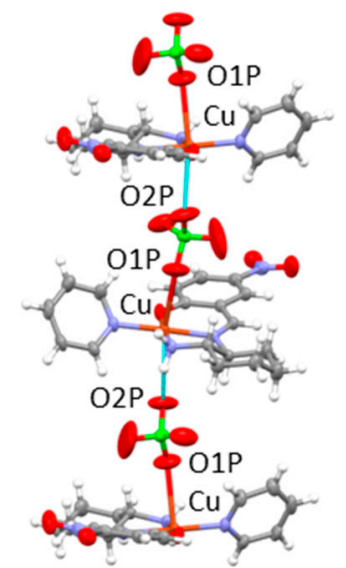

(a)

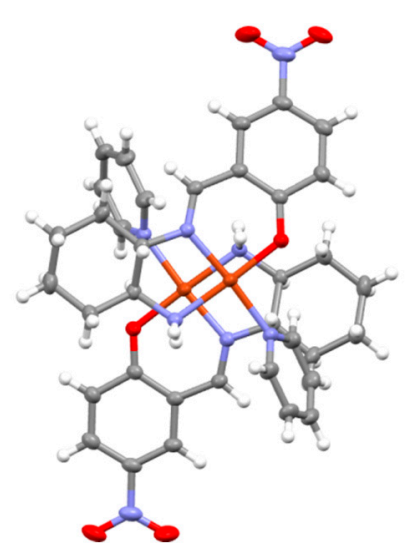

(b)

Figure 3. Fragments of crystal packing in $\mathbf{1 c}$ viewed along (a) $a$ and (b) $c$; displacement ellipsoids are drawn at $30 \%$ probability; color code: $\mathrm{Cu}=$ orange, $\mathrm{Cl}=$ green, $\mathrm{O}=$ red, $\mathrm{N}=$ light blue, $\mathrm{C}=$ grey, $\mathrm{H}=$ white (intermolecular contacts are shown as cyan lines; perchlorate anions are not shown in (b) for clarity).

\subsection{Absorption Spectroscopy}

The electronic spectra in the solid state of $\mathbf{1} \mathbf{b}, \mathbf{1} \mathbf{b}^{\prime}, \mathbf{1} \mathbf{c}, \mathbf{2} \mathbf{a}, \mathbf{2} \mathbf{b}$, and $\mathbf{2} \mathbf{c}$ are reported in Figure $4 a$ in the $12,000-50,000 \mathrm{~cm}^{-1}(900-200 \mathrm{~nm})$ region. In all cases, it is possible to recognise a well-isolated $d-d$ transition in the $17,300-17,800 \mathrm{~cm}^{-1}(562-578 \mathrm{~nm})$ range, with the exception of $\mathbf{1} \mathbf{b}^{\prime}$, in which the band appears to be much broader and weaker. This clearly reflects the different ligand field given by the substitution of a water molecule by a pyridine ligand. Charge transfer (CT) and $\pi \rightarrow \pi^{*}$ transitions start to appear above $20,000 \mathrm{~cm}^{-1}$. The introduction of the OMe group on going from $\mathbf{2 a}$ to $\mathbf{2} \mathbf{b}$ leads to the absorption at lower wavenumbers, as expected for the favoured ligand-to-metal charge transfer (LMCT) transition by the presence of the donor group [38,39]. When moving to $\mathbf{2 c}$, even if the push-pull substitution is equal to $\mathbf{2} \mathbf{b}$, the LMCT band moves further to lower energies, which might be caused by the presence of close molecules with short intermolecular interactions [53], favoured by the smaller steric hindrance of the cyclohexyl ring compared with the two phenyl rings on the diamine bridge [60]. The same behaviour is present when comparing $\mathbf{1 b}$ and $\mathbf{1 c}$, where the donor sal moiety is absent, which can thus confirm the occurrence of favoured electronic transitions in chxn derivatives. Above $30,000 \mathrm{~cm}^{-1}$, all spectra appear very similar owing to further $\pi \rightarrow \pi^{*}$ transitions. 


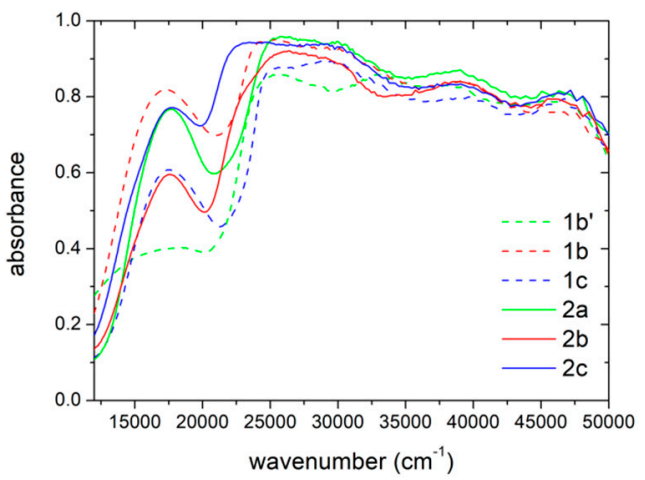

(a)

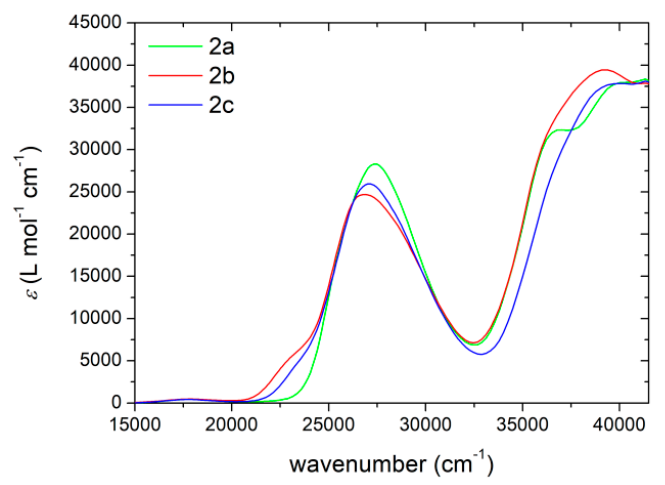

(b)

Figure 4. UV/visible absorption spectra of (a) $\mathbf{1 b}, \mathbf{1} \mathbf{b}^{\prime}, \mathbf{1 c}, \mathbf{2} \mathbf{a}, \mathbf{2} \mathbf{b}$, and $\mathbf{2 c}$ in the solid state and (b) $\mathbf{2 a}, \mathbf{2 b}$, and $2 \mathrm{c}$ in $2 \times 10^{-5} \mathrm{CHCl}_{3}$ solutions (zoom of the $d-d$ transition region from 12,500 to $20,000 \mathrm{~cm}^{-1} \mathrm{can}$ be found in Figure S4 in SM).

Solution studies were performed on non-ionic derivatives 2 in $\mathrm{CHCl}_{3}$ solutions from $10^{-3}$ to $2 \times 10^{-5} \mathrm{~mol} \mathrm{~L}^{-1}$ (see Figure $4 \mathbf{b}$ ). The $d-d$ transition in $\mathbf{2 a}, \mathbf{2} \mathbf{b}$, and $\mathbf{2 c}$ appears as a relatively weak band at about 17,730-17,860 $\mathrm{cm}^{-1}\left(560-564 \mathrm{~nm}\right.$ ) with $\varepsilon \sim 500 \mathrm{~L} \mathrm{~mol}^{-1} \mathrm{~cm}^{-1}$ (see Figure S4 in SM for a zoom of the 12,500-20,000 $\mathrm{cm}^{-1}$ region), as expected for copper(II) complexes with a rigid square planar geometry given by both chiral [51,52,54] and achiral [38] $\mathrm{N}_{2} \mathrm{O}_{2}$ salen-type ligands, with no apparent effect given by the diamine bridge or substituents. Position, shape, and intensity of the $d-d$ band also follow the Lambert-Beer law, which suggests the absence of stacked molecules in solution at a concentration lower than $10^{-3} \mathrm{~mol} \mathrm{~L}^{-1}$. In the $20,000-32,000 \mathrm{~cm}^{-1}$ range, there is an intense absorption with $\varepsilon$ coefficients as high as $27,000 \mathrm{~L} \mathrm{~mol}^{-1} \mathrm{~cm}^{-1}$, which can be attributed to a convolution of CT transitions $[52,80]$. In particular, the position of the LMCT band depends on the substituents present on the molecular skeleton, as confirmed by its visibility in the lowest energy side as a shoulder at about $22,500 \mathrm{~cm}^{-1}\left(\varepsilon \sim 4000 \mathrm{~L} \mathrm{~mol}^{-1} \mathrm{~cm}^{-1}\right)$ in $\mathbf{2 b}$ and $\mathbf{2 c}$ bearing the OMe group, while it moves below the strongest intra-ligand charge transfer (ILCT) $\pi \rightarrow \pi^{*}$ transitions in $\mathbf{2 a}$, where there is no donor substituent. In fact, we previously confirmed the nature of the LMCT band on derivatives with non-chiral en and tn bridges, where the HOMO orbital depicted by theoretical calculations is mainly localized on the D-sal moiety $[38,39]$. In the UV region above $33,000 \mathrm{~cm}^{-1}$, a strong absorption due to further $\pi \rightarrow \pi^{*}$ transitions appears [80], with noticeable differences among the three complexes. In particular, compounds with dpen possess a stronger absorbance at lower energies, probably given by transitions where the aromatic rings of the diamine bridge are involved. Comparing $\mathbf{2 a}$ and $\mathbf{2} \mathbf{b}$, the latter shows a more pronounced maximum at $39,370 \mathrm{~cm}^{-1}(254 \mathrm{~nm})$ and $\varepsilon=40,600 \mathrm{~L} \mathrm{~mol}^{-1} \mathrm{~cm}^{-1}$, promoted by the presence of the OMe group.

Ionic complexes $\mathbf{1}$ are not soluble in non-coordinating solvents, while they are, for example, in methanol. Nevertheless, they probably undergo substitution of the pyridine ligand once in $\mathrm{MeOH}[78,81]$, so that the spectrum corresponds to the solvated species $[\mathrm{Cu}(\mathrm{L})(\mathrm{MeOH})]^{+}$. To overcome this drawback, studies in solution were performed in $\mathrm{MeOH}$ (from $10^{-3}$ to $4 \times 10^{-5} \mathrm{~mol} \mathrm{~L}^{-1}$ ), adding increasing amounts of pyridine to the most diluted solution. The obtained spectra of $\mathbf{1 b}$ and $\mathbf{1 c}$ in $\mathrm{MeOH}$ (reported in Figure S5 in SM) are not too dissimilar from those of derivatives 2, except for shifted $\left(16,050 \mathrm{~cm}^{-1}\right.$, $623 \mathrm{~nm}$ ) and weaker $\left(135 \mathrm{~L} \mathrm{~mol}^{-1} \mathrm{~cm}^{-1}\right) d-d$ transitions. Upon addition of pyridine, this transition moves toward higher energies, $17,670 \mathrm{~cm}^{-1}(566 \mathrm{~nm})$, and higher intensity, $\varepsilon=300$ and $235 \mathrm{~L} \mathrm{~mol}^{-1} \mathrm{~cm}^{-1}$, for $\mathbf{1 b}$ and $\mathbf{1 c}$, respectively. This seems to confirm the $[\mathrm{Cu}(\mathrm{L})(\mathrm{MeOH})]^{+} \rightarrow[\mathrm{Cu}(\mathrm{L})(\mathrm{py})]^{+}$back conversion in solution, owing to the stronger ligand field given by pyridine with respect to $\mathrm{MeOH}$. Nevertheless, the LMCT + ILCT transitions are not affected by the coordination of either py or $\mathrm{MeOH}$. 


\subsection{DFT Structural, Electronic, and NLO Properties}

In view of theoretically evaluating the molecular nonlinear optical properties of the investigated compounds, DFT geometry optimizations were performed on the cations of $\mathbf{1 a}-\mathbf{c}$. The experimental bond lengths were satisfactorily reproduced (see Table 2), with the exceptions of only the Cu-N1 and $\mathrm{Cu}-\mathrm{N} 3$ distances, which are systematically longer in the optimized structures. This reflects the greater tendency of such bonds to be deformed by packing forces with respect to the other coordinating bonds. For the same reason, the dihedral angles between the $\mathrm{N}_{3} \mathrm{O}$ and pyridine l.s. planes, which are virtually the same in the optimized structures, are very different from the $\mathrm{X}$-ray values, displaying large variations not only from one structure to another, but also in the same structure, as observed in $\mathbf{1 b}$. The comparison of the coordinating bond lengths in $\mathbf{1 a - c}$ does not reveal significant differences, as expected from the analogous electronic environment around the copper ion in the three structures.

DFT geometry optimizations were also performed on $\mathbf{2 a}-\mathbf{c}$, for which X-ray data were not available, owing to the well-assessed reliability of DFT in reproducing the molecular features of this class of complexes [38,39]. As we previously observed and theoretically reproduced in the [Cu(5-A-5'-D-salen)] derivatives [38], the $\mathrm{NO}_{2}$ group is more efficient in modulating the coordination geometry with respect to the OMe one. Such influence is mainly manifested in the $\mathrm{Cu}-\mathrm{O}$ bonds, with elongation of $\mathrm{Cu}-\mathrm{O} 1$ (A side) and a concomitant decrease of $\mathrm{Cu}-\mathrm{O} 2$ (D side) bond lengths. The $\mathrm{Cu}-\mathrm{N}$ bonds are less affected by the presence of the $\mathrm{NO}_{2}$ group, with a slightly more elongated $\mathrm{Cu}-\mathrm{N} 2$ (A side) with respect to $\mathrm{Cu}-\mathrm{N} 1$ (D side) bond lengths (Table 3, Figure 5, and Figure S6 in SM). Comparing 2b and 2c, having the same $\left(\mathrm{NO}_{2}, \mathrm{OMe}\right)$ push-pull pattern, but a different diamine (dpen vs. chxn, respectively) bridge, the most remarkable difference lies in the dihedral angle between the 1.s. planes through the two sal moieties, which is higher in $\mathbf{2 c}\left(12.33^{\circ}\right)$ with respect to $\mathbf{2 a}\left(10.20^{\circ}\right)$ and $\mathbf{2 b}\left(10.28^{\circ}\right)$. The reason for this difference can be probably found in the greater steric demand of the cyclohexyl ring with respect to the dpen bridge.

Table 3. Selected interatomic distances $(\AA)$ and angles $\left(^{\circ}\right)$ in $\mathbf{2 a}, \mathbf{2 b}$, and $\mathbf{2 c}$ from UM06/6-311++G(d,p) calculations (see Figure 5 and Figure S6 in SM for main atom labelling).

\begin{tabular}{|c|c|c|c|}
\hline & 2a $\left(\mathrm{NO}_{2}, \mathrm{H}\right)$ & $2 \mathrm{~b}\left(\mathrm{NO}_{2}, \mathrm{OMe}\right)$ & $2 \mathrm{c}\left(\mathrm{NO}_{2}, \mathrm{OMe}\right)$ \\
\hline $\mathrm{Cu}-\mathrm{N} 1^{1}$ & 1.952 & 1.954 & 1.957 \\
\hline $\mathrm{Cu}-\mathrm{N} 2{ }^{1}$ & 1.966 & 1.967 & 1.969 \\
\hline $\mathrm{Cu}-\mathrm{O} 1^{1}$ & 1.928 & 1.913 & 1.931 \\
\hline $\mathrm{Cu}-\mathrm{O} 2^{1}$ & 1.903 & 1.897 & 1.895 \\
\hline $\mathrm{O} 1-\mathrm{Cu}-\mathrm{O} 2$ & 90.51 & 90.62 & 91.23 \\
\hline $\mathrm{N} 1-\mathrm{Cu}-\mathrm{N} 2$ & 84.34 & 84.30 & 84.02 \\
\hline A-sal $\angle$ D-sal ${ }^{2}$ & 10.20 & 10.28 & 12.33 \\
\hline
\end{tabular}

${ }^{1} \mathrm{O} 1$ and $\mathrm{N} 2$ on the acceptor side, $\mathrm{O} 2$ and $\mathrm{N} 1$ on the donor side; ${ }^{2}$ dihedral angle between the l.s. plane through the nine $\mathrm{C} / \mathrm{N} / \mathrm{O}$ atoms of the two sal moieties, excluding $\mathrm{A}$ or $\mathrm{D}$.

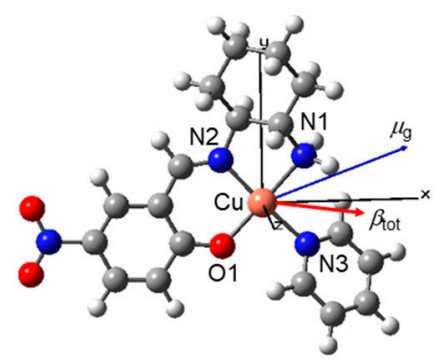

(a)

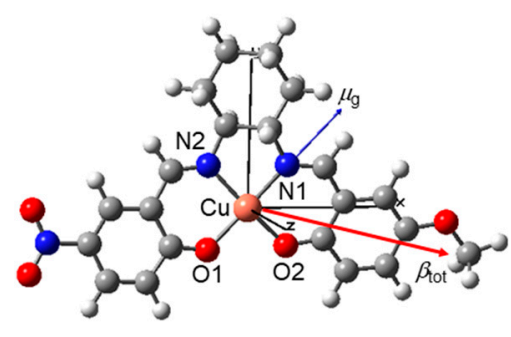

(b)

Figure 5. Optimized geometries of (a) cation of $\mathbf{1 c}$ and (b) $2 \mathbf{c}$ with $\mu_{\mathrm{g}}$ and $\beta_{\text {tot }}$ vectors expressed in arbitrary units; color code: $\mathrm{Cu}=$ light orange, $\mathrm{O}=$ red, $\mathrm{N}=$ blue, $\mathrm{C}=$ grey, $\mathrm{H}=$ white. 
As expected, the cations of compounds $\mathbf{1 a}, \mathbf{1} \mathbf{b}$, and $\mathbf{1} \mathbf{c}$ are very similar from an electronic point of view (see Table 4). Using the copper ion as the origin of the Cartesian reference (see computational details), their dipole moments, about 13.5 D, and hyperpolarizability vectors $\beta_{\text {tot }}$, about $23-24 \times 10^{-30} \mathrm{~cm}^{5} \mathrm{esu}^{-1}$, reflect an almost indistinguishable behavior of the compounds at the molecular level, in both the ground and the excited state. Compounds $\mathbf{2} \mathbf{a}, \mathbf{2} \mathbf{b}$, and $\mathbf{2 c}$, on the other hand, while having similar dipole moments (13.02, 12.26 , and $12.34 \mathrm{D}$ ), show increasing values of $\beta_{\text {tot }}$ from 39.7 to 49.2 and $49.6 \times 10^{-30} \mathrm{~cm}^{5} \mathrm{esu}^{-1}$, going from $\mathbf{2} \mathbf{a}$ to $\mathbf{2 b}$ and $\mathbf{2} \mathbf{c}$, as a consequence of the presence of the donor group OMe in the latter compounds. These values are quite similar to those previously obtained for the [Cu(5-A-5'-D-salen)] analogues with $\left(\mathrm{NO}_{2}, \mathrm{H}\right)$ and $\left(\mathrm{NO}_{2}, \mathrm{OMe}\right)$ substitutions [38,39], indicating, at the molecular level, the almost irrelevant influence of the ethylene substituents (en vs. dpen vs. chxn) on the electronic properties.

Table 4. Computed ${ }^{1}$ dipole moments $\left(\mu_{\mathrm{g}}, \mu_{\mathrm{x}}, \mu_{\mathrm{y}}\right.$, and $\left.\mu_{\mathrm{z}}, \mathrm{D}\right)$, SHG $(\lambda=1.907 \mu \mathrm{m})$ hyperpolarizabilities $\left(\beta_{\text {tot }}, \beta_{\text {vec }}, \beta_{\mathrm{x}}, \beta_{\mathrm{y}}\right.$ and $\left.\beta_{\mathrm{z}}, 10^{-30} \mathrm{~cm}^{5} \mathrm{esu}^{-1}\right)$ in $\mathrm{CHCl}_{3}$, and angle $\left(\theta,{ }^{\circ}\right)$ between $\mu_{\mathrm{g}}$ and $\beta_{\text {tot }}$ vectors for cations of $\mathbf{1 a}-\mathbf{c}$ and for $\mathbf{2 a}-\mathbf{c}$.

\begin{tabular}{ccccccc}
\hline & $\mathbf{1 a}$ & $\mathbf{1 b}$ & $\mathbf{1 c}$ & $\mathbf{2 a}$ & $\mathbf{2 b}$ & $\mathbf{2 c}$ \\
\hline$\mu_{\mathrm{x}}$ & 12.66 & 12.34 & 12.66 & 7.86 & 8.47 & 8.48 \\
$\mu_{\mathrm{y}}$ & 4.69 & 5.42 & 4.71 & 10.35 & 8.81 & 8.96 \\
$\mu_{\mathrm{z}}$ & -2.12 & -0.56 & 0.71 & 0.88 & 0.95 & 0.12 \\
$\mu_{\mathrm{g}}$ & 13.66 & 13.49 & 13.53 & 13.02 & 12.26 & 12.34 \\
$\beta_{\mathrm{x}}$ & 23.72 & 22.79 & 23.61 & 37.70 & 47.02 & 48.75 \\
$\beta_{\mathrm{y}}$ & -4.11 & -2.78 & -3.01 & -12.44 & -14.50 & -8.98 \\
$\beta_{\mathrm{z}}$ & 0.64 & -1.06 & 0.56 & -0.65 & -0.77 & -1.93 \\
$\beta_{\text {tot }}$ & 24.08 & 22.98 & 23.81 & 39.71 & 49.22 & 49.60 \\
$\beta_{\text {vec }}$ & 20.46 & 19.78 & 21.08 & 12.83 & 22.00 & 26.98 \\
$\theta$ & 31.8 & 30.6 & 27.7 & 71.2 & 63.5 & 57.0 \\
\hline
\end{tabular}

${ }^{1}$ Calculations were performed at the (CP)CAM-B3LYP/6-311++G(d,p)/IEFPCM $\left(\mathrm{CHCl}_{3}\right)$ level of theory on the $\mathrm{UM} 06 / 6-311++\mathrm{G}(\mathrm{d}, \mathrm{p})$ optimized geometries; see computational details section for the adopted reference frame to report the $\mu_{\mathrm{i}}$ and $\beta_{\mathrm{i}}$ components; hyperpolarizabilities are defined as $\beta_{\mathrm{tot}}=\left(\beta_{\mathrm{x}}{ }^{2}+\beta_{\mathrm{y}}{ }^{2}+\beta_{\mathrm{z}}{ }^{2}\right)^{1 / 2}$ and $\beta_{\mathrm{vec}}=\Sigma_{\mathrm{i}}\left(\mu_{\mathrm{i}}\right.$ $\left.\beta_{\mathrm{i}}\right) /|\mu|$, where $\beta_{\mathrm{i}}=(1 / 3) \Sigma_{\mathrm{j}}\left(\beta_{\mathrm{ijj}}+\beta_{\mathrm{jij}}+\beta_{\mathrm{jij}}\right)$ [82]. In particular, $\beta_{\mathrm{tot}}=(5 / 3) \beta_{\|}$and $\beta_{\mathrm{vec}}=(5 / 3) \beta_{\|}(\mathrm{z})$, where $\beta_{\|}$and $\beta_{\|}(z)$ are the quantities printed in the Gaussian16 output, according to the Taylor convention [83].

\subsection{Solid-State NLO Properties}

The solid-state NLO response of powder samples $\mathbf{1 b}, \mathbf{1 c}, \mathbf{2} \mathbf{a}, \mathbf{2} \mathbf{b}$, and $\mathbf{2} \mathbf{c}$ was investigated using the Kurtz-Perry technique [47] @1.907 $\mu \mathrm{m}$, resulting in SHG efficiencies equal to 0.13, 0.44, 0.32, 0.19, and 0.30 times that of standard urea, respectively. Even if not high, these values are in line with those reported for the majority of similar Schiff base metal complexes $[45,46,64,65,84]$, and lower than those reported only for $\left[\mathrm{Mn}(\mathrm{Cl})\left(4,4^{\prime}-\mathrm{diNEt}_{2}\right.\right.$-sal-(1R,2R)-chxn)] [23,48] and [Ni(4,4'-diNEt 2 -sal-(1R,2R)-dpen)] [23,49], whose SHG efficiencies are up to 8 and 13 times that of urea, respectively.

Owing to the absence of the crystal structure of $\mathbf{2 a - c}$, only hypothesis to compare the molecular properties as described by theoretical calculations with the solid-state NLO data can be formulated in the case of derivatives with unsymmetrically-substituted tetradentate ligands. A possible explanation for the observed diminished $\chi^{(2)}$ is the unfavorable alignment of the chromophores, which probably still tend to couple in a head-to-tail fashion, in agreement with previous reports [38,39]. Anyway, the chirality conferred to the final complexes by the diamines prevents perfect alignment, resulting in a small, but non-zero solid-state NLO response. In particular, theoretical calculations gave reasonably similar $\beta_{\text {tot }}$ values ( 49.22 and $49.60 \times 10^{-30} \mathrm{~cm}^{5} \mathrm{esu}^{-1}$ ) for $\mathbf{2} \mathbf{b}$ and $\mathbf{2 c}$, respectively, bearing the same A-D substitution, while their SHG efficiencies are 0.19 and 0.30 times that of standard urea, which suggests a better performance of the chxn diamine bridge with respect to dpen. This is in opposition to what was observed

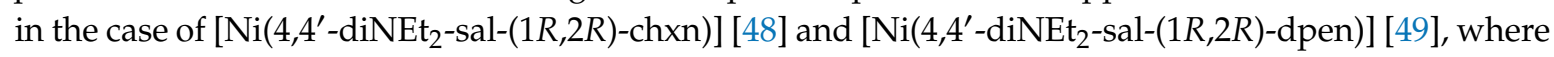
a higher SHG efficiency was achieved by the latter compound ( 9 vs. 0.3 times that of standard urea for 50-80 $\mu \mathrm{m}$ grain caliber) and ascribed to its higher degree of chirality [85] conferred by the spatial disposition of the two phenyl rings [49]. The opposite chirality of chxn employed in $2 \mathrm{c}$ with respect 
to $\left[\mathrm{Ni}\left(4,4^{\prime}\right.\right.$-diNEt ${ }_{2}$-sal-(1R,2R)-chxn)] does not have an effect because the solid-state NLO response depends on the molecular hyperpolarizability, the orientation of the molecule with respect to the crystalline reference frame, and the nature of the crystal point group [10] — properties that are coincident with those of the enantiomer of $2 \mathrm{c}$, that is, [Cu(5-NO$\left.\left.-\mathrm{NO}_{2}-5^{\prime}-\mathrm{OMe}-\mathrm{sal}-(1 R, 2 R)-\mathrm{ch} \times n\right)\right]$.

The same trend in the SHG efficiency can be drawn out for $\mathbf{1 b}$ (dpen) and $\mathbf{1 c}(\mathrm{chxn})$, where their experimental values are 0.13 and 0.44 times that of standard urea against similar computed $\beta_{\text {tot }}$ values of 22.98 and $24.08 \times 10^{-30} \mathrm{~cm}^{5} \mathrm{esu}^{-1}$, respectively. These values can be interpreted through both the analysis of degree of chirality and the relationship between microscopic $\beta_{x y z}$ and macroscopic $\beta_{X Y Z}$, with both pieces of information being affordable for these compounds thanks to their known crystal structure. Quantification of the degree of chirality with the continuous symmetry measures (CSM) formalism proposed by Avnir et al. [86], on a scale from 0 (achiral) to 100, gave a greater value in 1c (7.7948, only the cation: 1.9812 ) than in $\mathbf{1 b}$ (chain A: 4.3929, cation: 1.5796; chain B: 6.4284, cation: 0.5959), considering either the cations $[\mathrm{Cu}(\mathrm{L})(\mathrm{py})]^{+}$or the $[\mathrm{Cu}(\mathrm{L})(\mathrm{py})]\left(\mathrm{ClO}_{4}\right)$ assemblies. This would suggest a kind of correlation between solid-state NLO response and the degree of chirality.

On the other side, the relationships between microscopic and macroscopic optical nonlinearities can be derived considering that crystals of $\mathbf{1 b}$ belong to the $P 2{ }_{1} 2{ }_{1} 2_{1}$ orthorhombic space group with two cations in the asymmetric unit. For the 222 point group, there is only one phase matchable coefficient, $\beta_{X Y Z}=\sin 2 \Phi \cos \theta\left(\beta_{x y y}-\beta_{x x x} \sin ^{2} \theta\right)-\beta_{y x x} \cos 2 \Phi \sin 2 \theta[10]$, where $\Phi$ is the projection of the CT axis on the $a b$ plane and $a$, and $\theta$ is the angle between the CT axis and $c$ [87]. The optimal value of the angular factor is 0.192 , reached for $\Phi=45^{\circ}$ and $\theta=54.7^{\circ}$. On the basis of CP-DFT calculations on the $\mathbf{1 b}$ cation, the $\mathrm{CT}$ axis lies approximately along the $\mathrm{C} 4-\mathrm{Cu}$ direction (i.e., the $x$ axis, see Figure $\mathrm{S} 6 \mathrm{~b}$ in SM and Table 4), so that $\Phi=89^{\circ}$ and $\theta=75^{\circ}$ for molecule 1 of chain A in the asymmetric unit, while $\Phi=84^{\circ}$ and $\theta=32^{\circ}$ for molecule 2 of chain B. As only $\beta_{x x x}$ is significantly different from zero for $\mathbf{1 b}$ cation, both values of $\Phi$, close to $90^{\circ}$, result in very small macroscopic susceptibility $\beta_{X Y Z}$. In the case of 1c (tetragonal space group $P 4_{3}$, point group 4 ), the only non-zero macroscopic nonlinear susceptibilities are $\beta_{Z Z Z}=\beta_{x x x} \cos ^{3} \theta$ and $\beta_{Z Y Y}=\left(\beta_{x y y}+\beta_{x x x} \sin ^{2} \theta\right) \cos \theta / 2, \theta$ being the angle between the CT axis and the four-fold axis $Z$. The almost orthogonality between these two axis $\left(\theta=82^{\circ}\right)$, far from the optimal value $\theta=54.7^{\circ}$, explains the low NLO susceptibility of $\mathbf{1 c}$.

\section{Conclusions}

The synthesis, structural and spectroscopic characterizations, and SHG efficiencies using the Kurtz-Perry technique of mononuclear copper(II) complexes with either tridentate or tetradentate Schiff base ligands are reported here with the aim of investigating their NLO performances to the solid state. The synthetic copper(II)-templated approach for tridentate Schiff base ligands $\mathrm{L}^{-}$derived from salicylaldehydes and aliphatic diamines [77] is efficiently exploited here with the use of the chiral diamines chxn and dpen, allowing also to isolate the intermediate $\mathbf{1} \mathbf{b}^{\prime}$ with coordinated water molecule, further replaced by pyridine. Derivatives $\left[\mathrm{Cu}\left(\mathrm{L}^{\mathrm{a}-\mathrm{c}}\right)(\mathrm{py})\right]\left(\mathrm{ClO}_{4}\right)(\mathbf{1 a}-\mathbf{c})$ were then converted into compounds [Cu(5-A-5'-D-saldpen/chxn)] (2a-c) with chiral tetradentate Schiff base ligands, obtaining push-pull complexes in which the metal ion promotes an intense LMCT transition, as observed in the $\mathrm{UV} /$ vis absorption spectroscopy.

Despite the low solid-state NLO efficiencies of about $0.15-0.45$ times that of standard urea for all derivatives, these values are in line with other similar compounds, with the exclusion of only a few exceptional cases $[48,49]$. X-ray structure determination of $\mathbf{1 b}$ and $\mathbf{1} \mathbf{c}$, together with theoretical calculations on their NLO molecular response, allowed to ascribe their modest NLO susceptibilities to the non-optimal alignment of their $\mathrm{CT}$ axes with respect to the crystalline reference frame.

Supplementary Materials: The following are available online at http://www.mdpi.com/1996-1944/12/21/3595/s1, Figure S1: MS-ESI+ spectra of compounds $\mathbf{1 a}-\mathbf{c}, \mathbf{1} \mathbf{b}^{\prime}$ and $\mathbf{2 a}-\mathbf{c}$ registered in MeOH solution; Figure S2: FT-IR spectra of compounds $\mathbf{1 a}-\mathbf{c}, \mathbf{1} \mathbf{b}^{\prime}$, and $\mathbf{2 a}-\mathbf{c}$ registered as KBr disks; Figure S3: X-ray crystal structure of $\mathbf{1 a} \cdot 0.5 \mathrm{H}_{2} \mathrm{O}$ with atom numbering scheme; Figure S4: UV/visible absorption spectra in the $12,500-20,000 \mathrm{~cm}^{-1}$ range $(d-d$ transition region) of $\mathbf{2 a}, \mathbf{2} \mathbf{b}$, and $2 \mathrm{c}$ in $10^{-3} \mathrm{~mol} \mathrm{~L}^{-1} \mathrm{CHCl}_{3}$ solutions; Figure S5: UV/visible absorption spectra 
in different spectral ranges and different concentrations of $\mathbf{1 b}$ and $\mathbf{1} \mathbf{c}$ in $\mathrm{MeOH}$, and upon addition of pyridine; Figure S6: optimized geometries of $\mathbf{1 a}, \mathbf{1} \mathbf{b}, \mathbf{2} \mathbf{a}$, and $\mathbf{2 b}$.

Author Contributions: Conceptualization, L.R.; Methodology, L.R., A.F., G.M., and E.C.; Formal Analysis, L.R., A.F., G.M., and E.C.; Investigation, L.R., A.F., G.M., and E.C.; Resources, A.F., G.M., and A.P.; Data Curation, L.R.; Writing-Original Draft Preparation, L.R.; Writing-Review \& Editing, L.R.; Visualization, L.R. and A.F.; Supervision, L.R.; Project Administration, L.R. and A.P.; Funding Acquisition, L.R., G.M., and A.P.

Funding: This research was funded by the Italian Ministero dell'Istruzione, dell'Università e della Ricerca (MIUR).

Acknowledgments: A.F. would like to thank Elettra Synchrotron Light Laboratory (Trieste, Italy) for the use of the beamline XRD1.

Conflicts of Interest: The authors declare no conflict of interest. The founding sponsors had no role in the design of the study; in the collection, analyses, or interpretation of data; in the writing of the manuscript; and in the decision to publish the results.

\section{References}

1. Collins, R.J.; Nelson, D.F.; Schawlow, A.L.; Bond, W.; Garrett, C.G.B.; Kaiser, W. Coherence, Narrowing, Directionality, and Relaxation Oscillations in the Light Emission from Ruby. Phys. Rev. Lett. 1960, 5, 303-305. [CrossRef]

2. Franken, P.A.; Hill, A.E.; Peters, C.W.; Weinreich, G. Generation of Optical Harmonics. Phys. Rev. Lett. 1961, 7, 118-119. [CrossRef]

3. Boyd, R.W. Nonlinear Optics, 3rd ed.; Academic Press: Amsterdam, The Netherlands; Boston, MA, USA, 2008; ISBN 978-0-12-369470-6.

4. Prasad, P.N.; Williams, D.J. Introduction to Nonlinear Optical Effects in Molecules and Polymers; Wiley: New York, NY, USA, 1991; ISBN 978-0-471-51562-3.

5. Materials for Nonlinear Optics: Chemical Perspectives; Marder, S.R.; Sohn, J.E.; Stucky, G.D. (Eds.) ACS Symposium Series; American Chemical Society: Washington, DC, USA, 1991; ISBN 978-0-8412-1939-7.

6. Papadopoulos, M.G.; Sadlej, A.J.; Leszczynski, J. (Eds.) Non-Linear Optical Properties of Matter: From Molecules to Condensed Phases; Challenges and Advances in Computational Chemistry and Physics; Springer: Dordrecht, The Netherlands, 2006; ISBN 978-1-4020-4849-4.

7. Structure-Property Relationships in Non-Linear Optical Crystals I.; Wu, X.-T.; Chen, L. (Eds.) Structure and Bonding; Springer Berlin Heidelberg: Berlin/Heidelberg, Germany, 2012; Volume 144, ISBN 978-3-642-29617-8.

8. Wu, X.-T.; Chen, L. (Eds.) Structure-Property Relationships in Non-Linear Optical Crystals II.; Structure and Bonding; Springer Berlin Heidelberg: Berlin/Heidelberg, Germany, 2012; Volume 145, ISBN 978-3-642-29620-8.

9. Nonlinear Optics; Kamanina, N. (Ed.) InTech Europe: Rijeka, Croatia, 2012; ISBN 978-953-51-0131-4.

10. Zyss, J.; Oudar, J.L. Relations between microscopic and macroscopic lowest-order optical nonlinearities of molecular crystals with one- or two-dimensional units. Phys. Rev. A 1982, 26, 2028-2048. [CrossRef]

11. Humphrey, M.G. Ruthenium Alkynyl Complexes in Non-Linear Optics. Aus. J. Chem. 2018, 71, 731-742. [CrossRef]

12. Kaur, S.; Kaur, M.; Kaur, P.; Clays, K.; Singh, K. Ferrocene chromophores continue to inspire. Fine-tuning and switching of the second-order nonlinear optical response. Coord. Chem. Rev. 2017, 343, 185-219. [CrossRef]

13. Kodikara, M.S.; Stranger, R.; Humphrey, M.G. Computational studies of the nonlinear optical properties of organometallic complexes. Coord. Chem. Rev. 2018, 375, 389-409. [CrossRef]

14. Humphrey, M.G.; Schwich, T.; West, P.J.; Cifuentes, M.P.; Samoc, M. Nonlinear Optical Properties of Coordination and Organometallic Complexes. In Comprehensive Inorganic Chemistry II.; Elsevier: Amsterdam, The Netherlands, 2013; pp. 781-835. ISBN 978-0-08-096529-1.

15. Di Bella, S.; Dragonetti, C.; Pizzotti, M.; Roberto, D.; Tessore, F.; Ugo, R. Coordination and Organometallic Complexes as Second-Order Nonlinear Optical Molecular Materials. In Molecular Organometallic Materials for Optics; Bozec, H., Guerchais, V., Eds.; Springer Berlin Heidelberg: Berlin/Heidelberg, Germany, 2010; Volume 28, pp. 1-55. ISBN 978-3-642-01865-7.

16. Mingabudinova, L.R.; Vinogradov, V.V.; Milichko, V.A.; Hey-Hawkins, E.; Vinogradov, A.V. Metal-organic frameworks as competitive materials for non-linear optics. Chem. Soc. Rev. 2016, 45, 5408-5431. [CrossRef]

17. Lacroix, P.G.; Malfant, I.; Lepetit, C. Second-order nonlinear optics in coordination chemistry: An open door towards multi-functional materials and molecular switches. Coord. Chem. Rev. 2016, 308, 381-394. [CrossRef] 
18. Di Bella, S. Second-order nonlinear optical properties of transition metal complexes. Chem. Soc. Rev. 2001, 30, 355-366. [CrossRef]

19. Pfeiffer, P.; Breith, E.; Lübbe, E.; Tsumaki, T. Tricyclische orthokondensierte Nebenvalenzringe. Justus Liebig's Ann. Der Chem. 1933, 503, 84-130. [CrossRef]

20. Rigamonti, L. Schiff base metal complexes for second order nonlinear optics. La Chimica e L'Industria 2010, $118,122$.

21. Liu, X.; Manzur, C.; Novoa, N.; Celedón, S.; Carrillo, D.; Hamon, J.-R. Multidentate unsymmetrically-substituted Schiff bases and their metal complexes: Synthesis, functional materials properties, and applications to catalysis. Coord. Chem. Rev. 2018, 357, 144-172. [CrossRef]

22. Nayar, C.R.; Ravikumar, R. Review: Second order nonlinearities of Schiff bases derived from salicylaldehyde and their metal complexes. J. Coord. Chem. 2014, 67, 1-16. [CrossRef]

23. Lacroix, P.G. Second-Order Optical Nonlinearities in Coordination Chemistry: The Case of Bis(salicylaldiminato)metal Schiff Base Complexes. Eur. J. Inorg. Chem. 2001, 2001, 339-348. [CrossRef]

24. Di Bella, S.; Fragala, I.; Ledoux, I.; Diaz-Garcia, M.A.; Lacroix, P.G.; Marks, T.J. Sizable Second-Order Nonlinear Optical Response of Donor-Acceptor Bis(salicylaldiminato)nickel(II) Schiff Base Complexes. Chem. Mater. 1994, 6, 881-883. [CrossRef]

25. Di Bella, S.; Fragala, I.; Ledoux, I.; Marks, T.J. Role of Metal Electronic Properties in Tuning the Second-Order Nonlinear Optical Response of Coordination Complexes. A Combined Experimental and Theoretical Investigation of a Homologous Series of ( $\mathrm{N}, \mathrm{N}^{\prime}$-Disalicylidene-1,2-phenylenediaminato) $\mathrm{M}(\mathrm{II})(\mathrm{M}=\mathrm{Co}, \mathrm{Ni}, \mathrm{Cu})$ Complexes. J. Am. Chem. Soc. 1995, 117, 9481-9485.

26. Lacroix, P.G.; Di Bella, S.; Ledoux, I. Synthesis and Second-Order Nonlinear Optical Properties of New Copper(II), Nickel(II), and Zinc(II) Schiff-Base Complexes. Toward a Role of Inorganic Chromophores for Second Harmonic Generation. Chem. Mater. 1996, 8, 541-545. [CrossRef]

27. Di Bella, S.; Fragalà, I.; Ledoux, I.; Diaz-Garcia, M.A.; Marks, T.J. Synthesis, Characterization, Optical Spectroscopic, Electronic Structure, and Second-Order Nonlinear Optical (NLO) Properties of a Novel Class of Donor-Acceptor Bis(salicylaldiminato)nickel(II) Schiff Base NLO Chromophores. J. Am. Chem. Soc. 1997, 119, 9550-9557. [CrossRef]

28. Averseng, F.; Lacroix, P.G.; Malfant, I.; Lenoble, G.; Cassoux, P.; Nakatani, K.; Maltey-Fanton, I.; Delaire, J.A.; Aukauloo, A. Synthesis, Crystal Structure, and Second-Order Nonlinear Optical Properties of a New Bis(salicylaldiminato)nickel(II) Metal Complex. Chem. Mater. 1999, 11, 995-1002. [CrossRef]

29. Di Bella, S.; Fragalà, I. Synthesis and second-order nonlinear optical properties of bis(salicylaldiminato)M(II) metalloorganic materials. Synth. Metals 2000, 115, 191-196. [CrossRef]

30. Averseng, F.; Lacroix, P.G.; Malfant, I.; Périssé, N.; Lepetit, C.; Nakatani, K. Enhanced Second Harmonic Generation on Passing from a Mono- to a Dicopper(II) Bis(salicylaldiminato) Schiff Base Complex. Inorg. Chem. 2001, 40, 3797-3804. [CrossRef] [PubMed]

31. Di Bella, S.; Fragalà, I.; Ledoux, I.; Zyss, J. Dipolar Donor-Acceptor-Substituted Schiff Base Complexes with Large Off-Diagonal Second-Order Nonlinear Optical Tensor Components. Chem. Eur. J. 2001, 7, 3738-3743. [CrossRef]

32. Costes, J.P.; Lamère, J.F.; Lepetit, C.; Lacroix, P.G.; Dahan, F.; Nakatani, K. Synthesis, Crystal Structures, and Nonlinear Optical (NLO) Properties of New Schiff-Base Nickel(II) Complexes. Toward a New Type of Molecular Switch? Inorg. Chem. 2005, 44, 1973-1982. [CrossRef]

33. Di Bella, S.; Oliveri, I.P.; Colombo, A.; Dragonetti, C.; Righetto, S.; Roberto, D. An unprecedented switching of the second-order nonlinear optical response in aggregate bis(salicylaldiminato)zinc(II) Schiff-base complexes. Dalton Trans. 2012, 41, 7013-7016. [CrossRef] [PubMed]

34. Di Bella, S.; Fragalà, I.; Marks, T.J.; Ratner, M.A. Large Second-Order Optical Nonlinearities in Open-Shell Chromophores. Planar Metal Complexes and Organic Radical Ion Aggregates. J. Am. Chem. Soc. 1996, 118, 12747-12751. [CrossRef]

35. Averseng, F.; Lepetit, C.; Lacroix, P.G.; Tuchagues, J.P. Theoretical Investigation of the Effect of a Spin Transition on the Second-Order Molecular Hyperpolarizability of a Bis(salicylaldiminato)Fe II Schiff Base Complex. Chem. Mater. 2000, 12, 2225-2229. [CrossRef]

36. Di Bella, S.; Fragalà, I. Two-dimensional characteristics of the second-order nonlinear optical response in dipolar donor-acceptor coordination complexes. New. J. Chem. 2002, 26, 285-290. 
37. Di Bella, S.; Fragalà, I. Second-Order Nonlinear Optical Properties of Tetraaza-Coordinated Nickel(II) Complexes. Eur. J. Inorg. Chem. 2003, 2003, 2606-2611. [CrossRef]

38. Rigamonti, L.; Demartin, F.; Forni, A.; Righetto, S.; Pasini, A. Copper(II) Complexes of salen Analogues with Two Differently Substituted (Push-Pull) Salicylaldehyde Moieties. A Study on the Modulation of Electronic Asymmetry and Nonlinear Optical Properties. Inorg. Chem. 2006, 45, 10976-10989. [CrossRef]

39. Rigamonti, L.; Forni, A.; Righetto, S.; Pasini, A. Push-pull unsymmetrical substitution in nickel(II) complexes with tetradentate $\mathrm{N}_{2} \mathrm{O}_{2}$ Schiff base ligands: Synthesis, structures and linear-nonlinear optical studies. Dalton Trans. 2019, 48, 11217-11234. [CrossRef]

40. Gradinaru, J.; Forni, A.; Druta, V.; Tessore, F.; Zecchin, S.; Quici, S.; Garbalau, N. Structural, Spectral, Electric-Field-Induced Second Harmonic, and Theoretical Study of $\mathrm{Ni}(\mathrm{II}), \mathrm{Cu}(\mathrm{II}), \mathrm{Zn}(\mathrm{II})$, and VO(II) Complexes with $\left[\mathrm{N}_{2} \mathrm{O}_{2}\right]$ Unsymmetrical Schiff Bases of S-Methylisothiosemicarbazide Derivatives. Inorg. Chem. 2007, 46, 884-895. [CrossRef] [PubMed]

41. Trujillo, A.; Fuentealba, M.; Carrillo, D.; Manzur, C.; Ledoux-Rak, I.; Hamon, J.-R.; Saillard, J.-Y. Synthesis, Spectral, Structural, Second-Order Nonlinear Optical Properties and Theoretical Studies on New Organometallic Donor-Acceptor Substituted Nickel(II) and Copper(II) Unsymmetrical Schiff-Base Complexes. Inorg. Chem. 2010, 49, 2750-2764. [CrossRef] [PubMed]

42. Zhang, J.; Zhong, C.; Zhu, X.; Tam, H.-L.; Li, K.-F.; Cheah, K.-W.; Wong, W.-Y.; Wong, W.-K.; Jones, R.A. Synthesis and two-photon absorption properties of unsymmetrical metallosalophen complexes. Polyhedron 2013, 49, 121-128. [CrossRef]

43. Celedón, S.; Dorcet, V.; Roisnel, T.; Singh, A.; Ledoux-Rak, I.; Hamon, J.-R.; Carrillo, D.; Manzur, C. Main-Chain Oligomers from $\mathrm{Ni}^{\mathrm{II}}$ - and $\mathrm{Cu}^{\mathrm{II}}$-Centered Unsymmetrical $\mathrm{N}_{2} \mathrm{O}_{2}$ Schiff-Base Complexes: Synthesis and Spectral, Structural, and Second-Order Nonlinear Optical Properties: Oligomers from Ni II and $\mathrm{Cu}$ II Schiff-Base Complexes. Eur. J. Inorg. Chem. 2014, 2014, 4984-4993. [CrossRef]

44. Novoa, N.; Roisnel, T.; Hamon, P.; Kahlal, S.; Manzur, C.; Ngo, H.M.; Ledoux-Rak, I.; Saillard, J.-Y.; Carrillo, D.; Hamon, J.-R. Four-coordinate nickel(II) and copper(II) complex based ONO tridentate Schiff base ligands: Synthesis, molecular structure, electrochemical, linear and nonlinear properties, and computational study. Dalton Trans. 2015, 44, 18019-18037. [CrossRef]

45. Chiang, W.; Thompson, M.E.; Vanengen, D. Synthesis and nonlinear optical properties of inorganic coordination polymers. Spec. Publ. R. Soc. Chem. 1991, 91, 210-2016.

46. Chiang, W.; Vanengen, D.; Thompson, M.E. Second-order non-linear optical properties of Fe(SALEN) complexes. Polyhedron 1996, 15, 2369-2376. [CrossRef]

47. Kurtz, S.K.; Perry, T.T. A Powder Technique for the Evaluation of Nonlinear Optical Materials. J. Appl. Phys. 1968, 39, 3798-3813. [CrossRef]

48. Lenoble, G.; Lacroix, P.G.; Daran, J.C.; Di Bella, S.; Nakatani, K. Syntheses, Crystal Structures, and NLO Properties of New Chiral Inorganic Chromophores for Second-Harmonic Generation. Inorg. Chem. 1998, 37, 2158-2165. [CrossRef]

49. Averseng, F.; Lacroix, P.G.; Malfant, I.; Dahan, F.; Nakatani, K. Synthesis, crystal structure and solid state NLO properties of a new chiral bis(salicylaldiminato)nickel(II) Schiff-base complex in a nearly optimized solid state environment. J. Mater. Chem. 2000, 10, 1013-1018. [CrossRef]

50. Zyss, J.; Chemla, D.S.; Nicoud, J.F. Demonstration of efficient nonlinear optical crystals with vanishing molecular dipole moment: Second-harmonic generation in 3-methyl-4-nitropyridine-1-oxide. J. Chem. Phys. 1981, 74, 4800-4811. [CrossRef]

51. Downing, R.S.; Urbach, F.L. Circular dichroism of square-planar, tetradentate Schiff base chelates of copper(II). J. Am. Chem. Soc. 1969, 91, 5977-5983. [CrossRef]

52. Pasini, A.; Gullotti, M.; Ugo, R. Optically active complexes of Schiff bases. Part 4. An analysis of the circular-dichroism spectra of some complexes of different coordination numbers with quadridentate Schiff bases of optically active diamines. J. Chem. Soc. Dalton Trans. 1977, 4, 346-356. [CrossRef]

53. Bernardo, K.; Leppard, S.; Robert, A.; Commenges, G.; Dahan, F.; Meunier, B. Synthesis and Characterization of New Chiral Schiff Base Complexes with Diiminobinaphthyl or Diiminocyclohexyl Moieties as Potential Enantioselective Epoxidation Catalysts. Inorg. Chem. 1996, 35, 387-396. [CrossRef]

54. Zolezzi, S.; Decinti, A.; Spodine, E. Syntheses and characterization of copper(II) complexes with Schiff-base ligands derived from ethylenediamine, diphenylethylenediamine and nitro, bromo and methoxy salicylaldehyde. Polyhedron 1999, 18, 897-904. [CrossRef] 
55. Hirotsu, M.; Kuwamura, N.; Kinoshita, I.; Kojima, M.; Yoshikawa, Y.; Ueno, K. Steric, geometrical and solvent effects on redox potentials in salen-type copper(II) complexes. Dalton Trans. 2009, 37, 7678. [CrossRef]

56. Kleij, A.W. Nonsymmetrical Salen Ligands and Their Complexes: Synthesis and Applications. Eur. J. Inorg. Chem. 2009, 2009, 193-205. [CrossRef]

57. Wang, Y.; Stack, T.D.P. Galactose Oxidase Model Complexes: Catalytic Reactivities. J. Am. Chem. Soc. 1996, 118, 13097-13098. [CrossRef]

58. Belokon, Y.N.; North, M.; Kublitski, V.S.; Ikonnikov, N.S.; Krasik, P.E.; Maleev, V.I. Chiral salen-metal complexes as novel catalysts for asymmetric phase transfer alkylations. Tetrahedron Lett. 1999, 40, 6105-6108. [CrossRef]

59. Gao, J.; Reibenspies, J.H.; Martell, A.E. Structurally Defined Catalysts for Enantioselective Oxidative Coupling Reactions. Angew. Chem. Int. Ed. 2003, 42, 6008-6012. [CrossRef]

60. Bania, K.K.; Karunakar, G.V.; Goutham, K.; Deka, R.C. Enantioselective Henry Reaction Catalyzed by “Ship in a Bottle" Complexes. Inorg. Chem. 2013, 52, 8017-8029. [CrossRef] [PubMed]

61. Balakrishnan, C.; Theetharappan, M.; Kowsalya, P.; Natarajan, S.; Neelakantan, M.A.; Mariappan, S.S. Biocatalysis, DNA-protein interactions, cytotoxicity and molecular docking of $\mathrm{Cu}(\mathrm{II}), \mathrm{Ni}(\mathrm{II}), \mathrm{Zn}(\mathrm{II})$ and V(IV) Schiff base complexes. Appl. Organomet. Chem. 2017, 31, e3776. [CrossRef]

62. Behzad, M.; Seifikar Ghomi, L.; Damercheli, M.; Mehravi, B.; Shafiee Ardestani, M.; Samari Jahromi, H.; Abbasi, Z. Crystal structures and in vitro anticancer studies on new unsymmetrical copper(II) Schiff base complexes derived from meso-1,2-diphenyl-1,2-ethylenediamine: A comparison with related symmetrical ones. J. Coord. Chem. 2016, 69, 2469-2481. [CrossRef]

63. Bian, H.-D.; Wang, J.; Wei, Y.; Tang, J.; Huang, F.-P.; Yao, D.; Yu, Q.; Liang, H. Superoxide dismutase activity studies of $\mathrm{Mn}(\mathrm{III}) / \mathrm{Cu}(\mathrm{II}) / \mathrm{Ni}(\mathrm{II})$ complexes with Schiff base ligands. Polyhedron 2015, 90, 147-153. [CrossRef]

64. Korupoju, S.R.; Mangayarkarasi, N.; Ameerunisha, S.; Valente, E.J.; Zacharias, P.S. Formation of dinuclear macrocyclic and mononuclear acyclic complexes of a new trinucleating hexaaza triphenolic Schiff base macrocycle: Structure and NLO properties. J. Chem. Soc. Dalton Trans. 2000, 16, 2845-2852. [CrossRef]

65. Margeat, O.; Lacroix, P.G.; Costes, J.P.; Donnadieu, B.; Lepetit, C.; Nakatani, K. Synthesis, Structures, and Physical Properties of Copper(II)-Gadolinium(III) Complexes Combining Ferromagnetic Coupling and Quadratic Nonlinear Optical Properties. Inorg. Chem. 2004, 43, 4743-4750. [CrossRef]

66. Leslie, A.G.W. Jnt CCP4/ESF-EACMB. Newslett. Protein Crystallogr. 1992, 27, 30.

67. Evans, P. Jnt CCP4/ESF-EACMB. Newslett. Protein Crystallogr. 1997, 33, 22.

68. Bruker, SMART, SAINT and SADABS; Bruker AXS Inc.: Madison, WI, USA, 1997.

69. Sheldrick, G.M. Crystal structure refinement with SHELXL. Acta Crystallogr. C 2015, 71, 3-8. [CrossRef]

70. Farrugia, L.J. WinGX and ORTEP for Windows: An update. J. Appl. Crystallogr. 2012, 45, 849-854. [CrossRef]

71. Macrae, C.F.; Edgington, P.R.; McCabe, P.; Pidcock, E.; Shields, G.P.; Taylor, R.; Towler, M.; van de Streek, J. Mercury: Visualization and analysis of crystal structures. J. Appl. Crystallogr. 2006, 39, 453-457. [CrossRef]

72. Yanai, T.; Tew, D.P.; Handy, N.C. A new hybrid exchange-correlation functional using the Coulomb-attenuating method (CAM-B3LYP). Chem. Phys. Lett. 2004, 393, 51-57. [CrossRef]

73. Johnson, L.E.; Dalton, L.R.; Robinson, B.H. Optimizing Calculations of Electronic Excitations and Relative Hyperpolarizabilities of Electrooptic Chromophores. Acc. Chem. Res. 2014, 47, 3258-3265. [CrossRef] [PubMed]

74. Scalmani, G.; Frisch, M.J. Continuous surface charge polarizable continuum models of solvation. I. General formalism. J. Chem. Phys. 2010, 132, 114110. [CrossRef] [PubMed]

75. Renehan, M.F.; Schanz, H.-J.; McGarrigle, E.M.; Dalton, C.T.; Daly, A.M.; Gilheany, D.G. Unsymmetrical chiral salen Schiff base ligands. J. Mol. Cat. A Chem. 2005, 231, 205-220. [CrossRef]

76. Costes, J.-P.; Dahan, F.; Fernandez Fernandez, M.B.; Fernandez Garcia, M.I.; Garcia Deibe, A.M.; Sanmartin, J. General synthesis of 'salicylaldehyde half-unit complexes': Structural determination and use as synthon for the synthesis of dimetallic or trimetallic complexes and of 'self-assembling ligand complexes'. Inorg. Chim. Acta 1998, 274, 73-81. [CrossRef]

77. Rigamonti, L.; Cinti, A.; Forni, A.; Pasini, A.; Piovesana, O. Copper(II) Complexes of Tridentate Schiff Bases of 5-Substituted Salicylaldehydes and Diamines-The Role of the Substituent and the Diamine in the Formation of Mono-, Di- and Trinuclear Species-Crystal Structures and Magnetic Properties. Eur. J. Inorg. Chem. 2008, 2008, 3633-3647. [CrossRef] 
78. Rigamonti, L.; Forni, A.; Pievo, R.; Reedijk, J.; Pasini, A. Copper(II) compounds with NNO tridentate Schiff base ligands: Effect of subtle variations in ligands on complex formation, structures and magnetic properties. Inorg. Chim. Acta 2012, 387, 373-382. [CrossRef]

79. Fernandez Garcia, M.I.; Fondo, M.; Garcia Deibe, A.M.; Fernandez Fernandez, M.B.; gonzalez, A.M. Copper(II) Complexes with Asymmetrical Schiff Base Ligands Derived from 2-Acetylpyrazine. Z. Anorg. Allg. Chem. 2000, 626, 1985-1991. [CrossRef]

80. Waters, T.N.; Wright, P.E. Electronic absorption band assignments for copper(II) salicylaldimine complexes. J. Inorg. Nucl. Chem. 1971, 33, 359-363. [CrossRef]

81. Rigamonti, L.; Forni, A.; Pievo, R.; Reedijk, J.; Pasini, A. Synthesis, crystal structures and magnetic properties of dinuclear copper(II) compounds with NNO tridentate Schiff base ligands and bridging aliphatic diamine and aromatic diimine linkers. Dalton Trans. 2011, 40, 3381-3393. [CrossRef] [PubMed]

82. Kanis, D.R.; Ratner, M.A.; Marks, T.J. Design and construction of molecular assemblies with large second-order optical nonlinearities. Quantum chemical aspects. Chem. Rev. 1994, 94, 195-242. [CrossRef]

83. Willetts, A.; Rice, J.E.; Burland, D.M.; Shelton, D.P. Problems in the comparison of theoretical and experimental hyperpolarizabilities. J. Chem. Phys. 1992, 97, 7590-7599. [CrossRef]

84. Zhu, J.; Song, H.; Sun, J.; Yan, P.; Hou, G.; Li, G. Luminescence and nonlinear optics of 1D $\mathrm{N}, \mathrm{N}^{\prime}$-bis(salicylidene)-1,2-cyclohexanediamine lanthanide coordination polymers. Synth. Met. 2014, 192, 29-36. [CrossRef]

85. Buda, A.B.; der Heyde, T.A.; Mislow, K. On Quantifying Chirality. Angew. Chem. Int. Ed. Engl. 1992, 31, 989-1007. [CrossRef]

86. Zayit, A.; Pinsky, M.; Elgavi, H.; Dryzun, C.; Avnir, D. A web site for calculating the degree of chirality. Chirality 2011, 23, 17-23. [CrossRef]

87. Cariati, E.; Roberto, D.; Ugo, R.; Ford, P.C.; Galli, S.; Sironi, A. New Structural Motifs, Unusual Quenching of the Emission, and Second Harmonic Generation of Copper(I) Iodide Polymeric or Oligomeric Adducts with Para-Substituted Pyridines or trans-Stilbazoles. Inorg. Chem. 2005, 44, 4077-4085. [CrossRef]

(C) 2019 by the authors. Licensee MDPI, Basel, Switzerland. This article is an open access article distributed under the terms and conditions of the Creative Commons Attribution (CC BY) license (http://creativecommons.org/licenses/by/4.0/). 